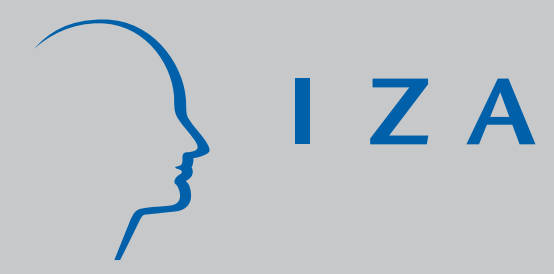

IZADP No. 2612

On the Emergence of Toyboys: Equilibrium Matching with Ageing and Uncertain Careers

Melvyn G. Coles

Marco Francesconi

February 2007 


\title{
On the Emergence of Toyboys: Equilibrium Matching with Ageing and Uncertain Careers
}

\author{
Melvyn G. Coles \\ University of Essex \\ Marco Francesconi \\ University of Essex and IZA \\ Discussion Paper No. 2612 \\ February 2007
}

IZA

P.O. Box 7240

53072 Bonn

Germany

Phone: +49-228-3894-0

Fax: +49-228-3894-180

E-mail: iza@iza.org

\begin{abstract}
Any opinions expressed here are those of the author(s) and not those of the institute. Research disseminated by IZA may include views on policy, but the institute itself takes no institutional policy positions.

The Institute for the Study of Labor (IZA) in Bonn is a local and virtual international research center and a place of communication between science, politics and business. IZA is an independent nonprofit company supported by Deutsche Post World Net. The center is associated with the University of Bonn and offers a stimulating research environment through its research networks, research support, and visitors and doctoral programs. IZA engages in (i) original and internationally competitive research in all fields of labor economics, (ii) development of policy concepts, and (iii) dissemination of research results and concepts to the interested public.
\end{abstract}

IZA Discussion Papers often represent preliminary work and are circulated to encourage discussion. Citation of such a paper should account for its provisional character. A revised version may be available directly from the author. 


\section{ABSTRACT \\ On the Emergence of Toyboys: Equilibrium Matching with Ageing and Uncertain Careers ${ }^{*}$}

Toyboy marriages (where the female partner is at least 5 years older than her male partner) have grown threefold since the 1970s in the United States and Britain. This paper examines this phenomenon using an equilibrium search framework in which becoming successful in the labour market takes time and fitness decays with age. Our framework hinges on contract incompleteness in the marriage market and the assumption that the marginal gain to marrying someone rich is greatest for someone poor. With this structure we can explain why successful (older) types might marry fitter (younger) and less successful types. We show that toyboy marriages arise in equilibrium only when men and women have comparable labour market opportunities. U.S. and British data confirm this indicating that the probability that a woman is married to a toyboy increases by about 45 percent if, relative to her partner's, she is more educated and in a better paid job.

JEL Classification: J12, J16, J62

Keywords: two-sided search, marriage, ex-ante heterogeneity, non-transferable utility, ageing

Corresponding author:

Marco Francesconi

Department of Economics

University of Essex

Colchester CO4 3SQ

United Kingdom

E-mail: mfranc@essex.ac.uk

\footnotetext{
${ }^{*}$ We are grateful for the permission of the Office for National Statistics to use the Longitudinal Study data and for the support provided by Chris Marshall and Jo Tomlinson from the Centre for Longitudinal Study Information and User Support (CeLSIUS). We thank Ken Burdett, John Knowles, Randy Wright, and seminar participants at Essex and UPenn for comments and suggestions.
} 


\section{Introduction}

Throughout the world and for many centuries, women married younger than men on average (Hajnal 1965; Spuhler 1972; United Nations 1990). ${ }^{1}$ This regularity has been documented for both industrialized and developing countries (e.g., Dixon 1971; Casterline et al. 1986). Since the 1960s, however, the age difference between the sexes at marriage has declined substantially in many places, although it has not entirely disappeared (Schoen and Canudas-Romo 2005; Office for National Statistics 2006). A trend which has accompanied this decline and has been overlooked by social analysts is the emergence of 'toyboys', that is, a greater number of women marrying younger men. Figure 1 shows the proportion of couples in which the woman is five or more years older than her male partner (referred to as a toyboy) and the proportion of couples in which the man is five or more years older than his female partner (a toygirl) in the United States and in Britain. ${ }^{2}$ Toyboy couples, as a fraction of all American couples, remained constant at about 3 percent during the twentieth century up to the 1970s. Over the two subsequent decades, though, there was an almost three-fold increase (8.3 percent in 2000). By contrast, the proportion of toygirl couples declined from 45 percent in 1900 to about 25 percent in 1980, and remained stable since then. The patterns among British couples are exactly the same, albeit observed over a shorter time frame.

Singles in the marriage market are likely to face frictions: it takes time to find someone with whom one is mutually compatible and might consider forming a life partnership. Figure 2 plots the hazard rates of entry into first partnership by age and gender in Britain. ${ }^{3}$ Reflecting the fact that married women tend to have older partners, single women have higher hazard rates than single men until around age 28. The female hazard rate peaks at age 24 , while for men it peaks at around age 28. Although for ages greater than age 32 single men match slightly more quickly than women, the gap is small and often insignificant. The goal of this paper is to use a two-sided equilibrium search framework to explain both the emerging toyboy phenomenon (Figure 1) and the observed gender age differential in partnership formation (Figure 2).

Following Burdett and Coles (1997) and Smith (2006) there has been a large search lit-

\footnotetext{
${ }^{1}$ The terms 'marriage', 'partnership', and 'union' (including cohabitation) will be used interchangeably. Similarly, 'husband' (or 'wife') and 'partner' are synonymous.

${ }^{2}$ The U.S. data are from the Integrated Public Use Microdata Series (IPUMS) covering the period 1900-2000. The British data are from the Office for National Statistics (ONS) Longitudinal Study for the period 1971-2001. A more complete description of the data will be given in Section 4.

${ }^{3}$ The data used here are from the British Household Panel Survey 1991-2003 and will be described in Section 4.
} 
erature examining equilibrium marriage behaviour with ex-ante heterogeneous agents and non-transferable utility (NTU). ${ }^{4}$ The NTU approach assumes incomplete marriage contracts: that is, couples cannot contract on future actions within the household (see, among others, Lundberg and Pollak [2003] and Mazzocco [2006]). Therefore, when considering a marriage proposal, singles anticipate future partners' behaviour and take the expected payoff of the marriage as given. Importantly, this approach is naturally related to our other key assumption, that individual payoffs are increasing and submodular in wealth. Submodularity implies that it is always better to marry someone rich, but the marginal value of doing so is greatest for someone poor. In a frictionless world with complete contracting (transferable utility) this would lead to negative assortative matching, that is, the poorest marry the richest. The poor can achieve this by making utility side payments to the rich, for example signing a pre-nuptial contract to undertake most domestic chores and provide other services. Such contracts, however, are rarely (if ever) observed (Weitzman 1981, Nasheri 1998, Leech 2000). ${ }^{5}$ A likely reason for this is that domestic actions in the households are not fully verifiable in court. Given the absence of marriage contracts and that (ceteris paribus) it is better to marry someone rich, equilibrium matching instead implies the rich tend to marry the rich. ${ }^{6}$

This paper extends the equilibrium search approach in three fundamental ways. First, rather than the usual one characteristic case, singles have two characteristics: fitness and earned wages. The ideal partner is both super-fit and a high earner. Such a desirable single enjoys many marriage proposals and so can afford to be very selective when choosing a partner. Less advantaged singles have more modest expectations of who they might attract in the marriage market. Allowing for two characteristics is an important extension as it implies singles no longer have the same ranking over potential partners: depending on one's own type, some may have a stronger preference for a partner who is rich, others for a partner who is fit.

A second feature is that fitness is assumed to decay (exogenously) with age. ${ }^{7}$ Ageing implies that a single becomes gradually less desirable to others and, taking into account

\footnotetext{
${ }^{4}$ See Burdett and Coles (1999) for a survey. More recent papers which examine marriage markets in an NTU framework include Eeckhout (1999), Bloch and Ryder (2000), Chade (2001), Cornelius (2003), Burdett et al. (2004), Giolito (2004), Wong (2005), Smith (2006), Gautier et al. (2006), Masters (2006). Smith (2006) is a pioneering paper, with its origins in the early 1990s.

${ }^{5}$ Pre-nuptial utility side payments could compensate for future chore assignments (as in Choo and Siouw [2006]), but examples of such side payments are rare.

${ }^{6}$ This argument ignores that the threat of divorce and ex-post bargaining on the terms of trade might still support negative assortative matching (Shimer and Smith 2000). We discuss this possibility below.

${ }^{7}$ See also the studies by Giolito (2004), which considers declining fecundity, and Masters (2006), in which fitness is a one horse shay.
} 
the proposal strategies of all, singles optimally become less picky as they get older. But this does not mean that marriage hazard rates increase with age. Most singles marry when young and a steady state implies that the set of potential partners for a single rapidly thins with age. Although older singles compensate by becoming less selective, a steady state implies hazard rates decline at long ages. ${ }^{8}$

A third new feature is that earnings in the labour market evolve stochastically. Specifically, all start their careers in low wage jobs but some become successful, or are promoted, and thereafter earn high wages. The value of becoming successful in the labour market is not only a richer lifestyle, but also the ability to attract more desirable potential partners (if still single).

We consider two scenarios depending on whether women and men have equal or unequal career opportunities in the labour market. When women and men have equal career opportunities, market equilibrium implies there is no gender differential in hazard rates to first partnership. In this scenario, toyboys (and toygirls) arise as an equilibrium phenomenon. Submodular payoffs in wealth imply that a rich single has a relatively strong preference for a fit partner, while a poor single has a relatively strong preference for someone rich. As fitness is negatively correlated with age and success is positively correlated with age, this preference structure leads successful singles to match with younger and fitter (but not successful) individuals. Thus, the model predicts that toyboy relationships, where the woman is substantially older than her partner, will be characterised by the woman being relatively more successful than her partner in the labour market.

The other scenario instead assumes women have weaker career prospects than men in the labour market. For simplicity, we take the extreme case of no career prospects for women (which we label "glass ceilings"). ${ }^{9}$ This generates a gender age differential in hazard rates to first partnership for two reasons. First, career opportunities raise the option value of deferring marriage. This arises as high wage earners enjoy a better pick from the pool of potential partners than do low wage earners. If divorce is costly (or, in the extreme case, if marriage is an irreversible decision), the option value of deferred marriage is that a single might attract a more desirable partner in the future (if successful). If men have better career prospects than women, this option raises the reservation fitness rule of single

\footnotetext{
${ }^{8}$ By assumption there is no divorce. Chiappori and Weiss (2006) examine equilibrium divorce incentives where there is a thick market externality in the remarriage market.

${ }^{9}$ An extreme example of no career prospects is given by the "marriage bar" faced by British and American women in the nineteenth and early twentieth centuries, according to which a woman would have to leave employment when she married (Goldin 1991; Rose 1992). Other forms of lack of opportunities and "glass ceilings" are described in Blossfeld and Hakim (1997) and Goldin (2006).
} 
(currently unsuccessful) males.

Second, there is a claim effect. Marriage implies that a woman shares her partner's chance of becoming successful in the future. Should she instead wait for her potential partner to become successful first, then - by the time he achieves this - she might have aged sufficiently that the successful potential partner prefers someone younger. ${ }^{10}$ With no divorce, marriage gives the woman an equal claim on her partner's future success. If women have worse career prospects than men, this claim effect lowers the reservation fitness rules of single females. Equilibrium feedback effects further reinforce this gender differential. As single men are relatively more selective, women face smaller acceptance sets. By reducing the female return to remaining single, this lowers still further female reservation match values. The converse holds for men, and this feedback increases the gap between their reservation value rules. ${ }^{11}$ Decaying fitness and the result that men are more selective than women then imply that young women will marry more quickly than young men.

The final part of the paper examines the empirical implications of our model. First, we examine the characteristics of women whose partners are at least 5 years younger than themselves. We find that the strongest positive influences on the probability that a woman is married to a toyboy come from her education and occupation (or income) relative to her partner's. Being more educated and in a better paid occupation than her partner implies that the woman has a 45 percent higher probability to be in a toyboy partnership than the average woman in the population. Similar quantitative results emerge when, besides education, we consider income, rather than occupation. We also analyse average hazard rates to first union by age and gender and so obtain the estimates shown in Figure 2 above. Finally, these estimates and their theoretical underpinnings are discussed vis-à-vis the differential fecundity approach.

Besides our approach, there are two other related matching literatures. One assumes frictional matching with transferable utility. Burdett and Coles (1999), Shimer and Smith (2000), Teulings and Gautier (2004), Atakan (2006) endogenise payoffs by assuming that the terms of trade within marriage are determined by Nash bargaining with threat points equal to the value of continued search. ${ }^{12}$ This approach can be motivated by positing that

\footnotetext{
${ }^{10}$ Jane Austen's novel Persuasion describes precisely this situation. The heroine has no career prospects and finds her marital prospects decline with age. Her previously rejected suitor (handsome but impecunious) subsequently becomes rich and successful and is courted by the young(er) and beautiful.

${ }^{11}$ In a steady state framework with idiosyncratic match payoffs, Burdett and Wright (1998) show that this effect can support multiple equilibria.

${ }^{12}$ Other contributions in the marriage context include Lundberg and Pollak (1993), Aiyagari et al. (2000) and Eeckhout (2006) who assume that payoffs are determined non-cooperatively within the match. Chade and Ventura (2002) instead assume partners co-operate to maximise the sum of their individual utilities.
} 
marriage contracts are complete and the terms of trade reflect the agents' outside options at the start of the marriage. Alternatively, it could be justified by assuming that there are no marriage contracts but separations are costless. Thus, the terms of trade are determined by the threat of divorce and, in a stationary environment, no divorce costs imply that the value of divorce is the same as the original value of continued search. Divorce, however, is not costless. As argued by Hall (2005) in a labour market context, it may be that once the match is consummated, the ex-post terms of trade are determined by the threat of holdout within the marriage (inside options) rather than by the threat of walking out (outside options). Notice that ex-post Nash bargaining with symmetric inside threat points and equal bargaining powers imply that chores (and the benefit of chores done) are shared equally between partners. With no marriage contracts to determine the terms of trade, this bargaining structure yields an NTU specification.

The other approach stems from the frictionless marriage literature (e.g., Siow 1998; Bergstrom and Bagnoli 1993). Siow (1998) assumes that men and women have equal career prospects but women are fertile only when they are young and, differently from men, cannot have children when they are old. As the only purpose of marriage is to raise children, divorced older men who are successful marry young fertile women. This squeezes the marriage prospects of currently unsuccessful young men, and differential fecundity yields a positive age differential between men and women who marry. Giolito (2004) extends these insights to a search framework where female fecundity declines more quickly than male fecundity. We shall discuss these contributions and relate them to ours more fully in Section 4.

Bergstrom and Bagnoli (1993) explain the gender age differential by assuming that men have better career prospects than women as considered in one of our labour market scenarios. But they explain the age differential as the outcome of a signalling game where the probability of career success is private information. In equilibrium, the men who are most likely to succeed defer marriage and so signal their talents. Our paper shows that information asymmetries are not necessary to generate an age bias. All that is required is that: (a) divorce is costly; (b) career success increases desirability; and (c) more desirable types enjoy a better pick from the pool of potential partners. The possibility of career success then generates an option value to deferred marriage. If men have better, though uncertain, career options than women, then they will tend to marry later.

Following the description of the model, Section 2 characterises the equilibrium matching for each income dynamics case. Section 3 discusses the theoretical insights using a numerical example to illustrate the underlying economic forces. Section 4 then examines 
data on partnership rates and toyboys, and Section 5 concludes.

\section{A Marriage Market}

We consider a continuous-time infinite-horizon model, and throughout we only examine steady states. There are two sexes, male and female (indexed by $s=m, f$ ) with a continuum of each type and equal measures. At any point in time, an agent is characterised by a fitness parameter $x \in(0, \bar{x}]$. Although we assume steady state, each agent's fitness declines deterministically over time at rate $\delta>0$. All die at rate $q>0$ and discount the future at rate $r>0$.

There are earnings dynamics whereby a worker either earns a high wage or a low wage. A worker begins his/her career on a low wage, $w^{L}$, but becomes successful in the labor market according to a Poisson process with parameter $\lambda$. A successful worker earns a higher wage, $w^{H}>w^{L}$, and is successful for life. Let $W^{t}$ be the worker's expected discounted lifetime earnings through always participating in the labour market, where $t=L, H$ denotes the worker's current success in the labour market. ${ }^{13}$ Thus each single in the marriage market is characterised by their sex $s$ and $(x, t)$ describing their fitness and labour market success.

Let $G_{s}$ be the joint distribution of $(x, t)$ across currently unmatched agents of sex $s=m, f$. All matches are heterosexual and unmatched agents meet each other according to a Poisson process with parameter $\alpha$. There are constant returns to matching, so $\alpha$ does not depend on the number of singles. Matching is random in the sense that, given a contact, the type of the potential partner $(x, t)$ with sex $s$, denoted $\left(x_{s}, t_{s}\right)$, is considered as a random draw from $G_{s}$. If both agree to form a match, they exit the market forever (for simplicity, there is no divorce and partners die together). Their payoffs are described below. If at least one does not wish to form a match, they separate with no recall and continue search, while - if indifferent - a potential partner is always willing to match. All aim to maximise expected discounted lifetime utility.

Suppose that a man of type $\left(x_{m}, t_{m}\right)$ and a woman of type $\left(x_{f}, t_{f}\right)$ agree to form a match. Extending Burdett and Coles (1997), assume that the man's expected payoff is

$$
\pi_{m}\left(x_{m}, x_{f}, t_{m}, t_{f}\right)=x_{f}+\widehat{V}\left(W^{t_{m}}, W^{t_{f}}\right)
$$

while the woman enjoys

$$
\pi_{f}\left(x_{m}, x_{f}, t_{m}, t_{f}\right)=x_{m}+\widehat{V}\left(W^{t_{m}}, W^{t_{f}}\right) .
$$

\footnotetext{
${ }^{13}$ Of course, lifetime earnings, $W$, are conditional on the worker remaining in the labour market.
} 
Each has expected payoff equal to the fitness of their partner plus the expected discounted flow value of consumption. As explained in the Introduction, this NTU specification is consistent with ex-post Nash bargaining with symmetric inside threat points and equal bargaining powers: partners simply share the chores and the benefits of chores done. We set the net benefit of chores done to zero so that the added value of marriage here is twofold: consumption within the household is a public good (e.g. Chiappori and Weiss [2006] among others) and partners enjoy their spouses' fitness.

A critical assumption is that $\widehat{V}$ is submodular in wealth, i.e., given wealth (or expected lifetime earnings) $W^{L}<W^{H}$, then

$$
\widehat{V}\left(W^{H}, W^{H}\right)+\widehat{V}\left(W^{L}, W^{L}\right)<2 \widehat{V}\left(W^{H}, W^{L}\right)
$$

A simple motivating example is that when married, both partners participate in the labour market and so enjoy joint discounted lifetime earnings $W_{f}+W_{m}$. If utility is strictly concave in consumption, this implies

$$
\widehat{V}\left(W^{H}+W^{H}\right)+\widehat{V}\left(W^{L}+W^{L}\right)<2 \widehat{V}\left(W^{H}+W^{L}\right)
$$

and hence $\widehat{V}$ is submodular. To keep the algebra simple, however, we instead assume task specialisation within the family where

$$
\widehat{V}\left(W^{t_{m}}, W^{t_{f}}\right)=\max \left[W^{t_{m}}, W^{t_{f}}\right]
$$

The interpretation of (2) is that the partner with higher expected lifetime earnings continues to participate in the labour market, the other partner withdraws from the labour market to raise the family. ${ }^{14}$ Thus, their joint consumption payoff is $W^{H}$ if the partner in continuing employment is successful, and $W^{L}$ otherwise. The algebraic simplification obtained by using (2), rather than (1), is that the marginal value of marrying someone successful, when already successful, is zero rather than something relatively small. Hence, we have payoff structure

$$
\begin{aligned}
& \pi_{m}(.)=x_{f}+\max \left[W^{t_{m}}, W^{t_{f}}\right] \\
& \pi_{f}(.)=x_{m}+\max \left[W^{t_{m}}, W^{t_{f}}\right],
\end{aligned}
$$

which is submodular in wealth. The key implication of submodular payoffs is that it is always better to marry someone rich but the marginal value of doing so is greatest for someone poor.

\footnotetext{
${ }^{14}$ This household organisation structure is similar to that adopted in Booth and Coles (2006).
} 
Agents are assumed to be liquidity constrained (i.e., they cannot borrow against the possibility of being successful in the future, or against marrying someone who is successful) and so, while single, they consume their current earnings. Therefore, the flow payoff while single is $w^{L}$ if the worker is unsuccessful and $w^{H}$ if successful. ${ }^{15}$ Then, should a successful male match with a currently unsuccessful woman, he obtains payoff $x_{f}+W^{H}$. Being successful and getting married does not yield a less wealthy lifestyle. Rather his riches are a joint public good with his partner and, in addition, he enjoys his partner's fitness $x_{f}$. In contrast, being unsuccessful and marrying someone successful improves the quality of one's lifestyle.

The steady state distribution functions $G_{s}$ are also endogenously determined. We assume an exogenous inflow of new singles $g d t>0$ per instant $d t$. All entrants are initially unsuccessful and the endowed fitness of any given entrant is considered as a random draw from $J$, with support $(0, \bar{x}]$, and is the same for both sexes. This implies that all agents have strictly positive fitness. Following Burdett and Coles (1999), we solve for equilibrium in two steps. The first step takes $G_{s}$ as given and characterises the equilibrium matching strategies — we call this a matching equilibrium. Identifying a market equilibrium in addition requires finding a $G_{s}$ whose implied exit flows, in a matching equilibrium, equals the exogeneous entry flows $(g, J)$ and so is consistent with a steady state.

In what follows we describe market equilibria for three cases. In the first, we illustrate equilibrium for the simplest possible case: no income dynamics (i.e., $\lambda_{m}=\lambda_{f}=0$ ). The second case considers a symmetric labour market where $\lambda_{m}=\lambda_{f}=\lambda$, and thus women have equal opportunities in the labour market. We show that submodular preferences $\widehat{V}$ lead to toyboyism - successful singles are likely to marry less successful but fitter, and therefore younger, partners. The third case assumes an asymmetric matching market where it is the female partner who quits the labour market to raise the family. Perhaps reflecting such a family organisation, here young women have lower promotion prospects than young men in the labour market. For example, anticipating future motherhood, young women may be more willing to enter "dead end" jobs, or may be less motivated in fighting for career promotion, or the labour market might discriminate against them. For whatever reason, we consider the extreme case that promotion rates $\lambda_{f}=0$ for women and $\lambda_{m}=\lambda>0$ for men. Optimal household organisation then implies that the male continues to work: even if he is currently unsuccessful, he has a positive chance of being successful in the future.

\footnotetext{
${ }^{15}$ In Cole et al. (1991), agents strategically accumulate savings while single to attract a more desirable partner. Tractability, however, requires us to rule out this behaviour.
} 


\subsection{An Illustrative Case: $\lambda_{m}=\lambda_{f}=0$}

As the model structure is complicated, we use this simpler case to demonstrate clearly the structure of an equilibrium. We skip the formal proofs which are instead provided in the next subsection with $\lambda_{m}=\lambda_{f}>0$.

With no income dynamics and in a steady state, sequential search with no recall implies that the optimal decision rule of each single has the reservation fitness property. For example, a man with fitness $x$ has a reservation fitness rule $R(x)$ : he will only propose to a woman with fitness $x^{\prime} \geq R(x)$. In a symmetric equilibrium, let $P(x) \subseteq[0, \bar{x}]$ denote the proposal set for each single with fitness $x \in[0, \bar{x}]$; i.e., a single $x$ will propose to a single $x^{\prime}$ of the opposite sex if and only if $x^{\prime} \in P(x)$. The reservation fitness property implies $P(x)=[R(x), \bar{x}]$.

The optimal reservation fitness rule $R(x)$ depends not only on who will propose to him/her given current $x$, but also on who will propose in the future as fitness $x$ declines with age. Define the acceptance set $A(x)$ as the set of agents who will accept a proposal from a type $x \in[0, \bar{x}]$. Clearly,

$$
A(x)=\left\{x^{\prime} \in[0, \bar{x}]: x \in P\left(x^{\prime}\right)\right\}
$$

as those who will accept a marriage proposal from type $x$ are also those who are willing to propose to type $x$.

Let $V(x)$ denote the value of being single with fitness $x$ using an optimal proposal strategy. The next subsection will formally establish the Bellman equation:

$$
(r+q) V(x)+\delta x V^{\prime}(x)=w+\alpha \int_{x^{\prime} \in A(x)} \max \left[x^{\prime}+W-V(x), 0\right] d G\left(x^{\prime}\right),
$$

where in this case with $\lambda=0$, all enjoy the same wage $w$ and $W=w /(r+q)$. The left hand side of (5) describes the flow value of being single, taking into account that fitness decays at rate $\delta$. The right hand side describes the flow return, which is consumption $w$ while single plus the expected capital gain by meeting a single who will accept an $x$ proposal. Note that single $x$ proposes if the contacted single $x^{\prime}$ has sufficiently high fitness that the value of being married $x^{\prime}+W$ exceeds the value of remaining single $V(x)$. Otherwise, the single prefers to continue search.

The Bellman equation implies optimal reservation fitness $R(x)=V(x)-W$; i.e., the single proposes if and only if partner fitness $x^{\prime} \geq V(x)-W$. It will be shown that $V($.$) is a$ non-decreasing function (singles with greater fitness enjoy better acceptance sets) and so $R($.$) is also non-decreasing. In fact equilibrium will imply that it is continuous and strictly$ 
increasing in $x$, in which case the inverse function

$$
R^{-1}(x)=\max \left\{x^{\prime} \in[0, \bar{x}]: R\left(x^{\prime}\right) \leq x\right\}
$$

is well defined. This inverse function identifies the equilibrium acceptance set

$$
A(x)=\left[0, R^{-1}(x)\right]
$$

as those with $x^{\prime} \leq R^{-1}(x)$ have reservation fitness $R\left(x^{\prime}\right) \leq x$ and so accept an $x$ proposal, while those with higher $x^{\prime}$ have $R\left(x^{\prime}\right)>x$ and so reject an $x$ proposal. Substituting out $V(x)=R(x)+W$ in (5), the Bellman equation and the equilibrium acceptance set $A(x)$ implies $R($.$) solves the equilibrium condition$

$$
(r+q) R(x)+\delta x \frac{d R}{d x}=\alpha \int_{R(x)}^{R^{-1}(x)}[y-R(x)] d G(y) .
$$

Equilibrium also implies the boundary condition

$$
R(x) \rightarrow 0 \text { as } x \rightarrow 0
$$

This occurs as nobody proposes to an $x=0$ as there is no added value to forming such a match. As $x \rightarrow 0$, equilibrium matching implies the acceptance set $\left[0, R^{-1}(x)\right]$ shrinks to the singleton $\{0\}$, and reservation fitness correspondingly shrinks to zero.

A matching equilibrium (as defined in the following subsection) is a reservation match strategy $R($.$) which solves the differential equation (7) subject to the boundary condition$ (8), with (6) describing the inverse function $R^{-1}($.$) . Such a solution then yields an optimal$ proposal correspondence $P(x)=[R(x), \bar{x}]$ for all $x \in[0, \bar{x}]$, an acceptance correspondence $A(x)=\left[0, R^{-1}(x)\right]$ and a matching correspondence $M(x)=\left[R(x), R^{-1}(x)\right]$ where a match occurs if and only if contacted $x^{\prime} \in M(x)$. It is straightforward to show such a matching equilibrium exists and is unique for any $G$.

Burdett and Coles (1997) solve the above problem with no decay $(\delta=0)$ and show that equilibrium matching implies a class structure (also see Smith (2006)). Equilibrium implies a partition of the line $[0, \bar{x}]$ into disjoint matching sets $\left[x_{n}, x_{n-1}\right)$ where $x_{n}<x_{n-1}$ is defined recursively by

$$
(r+q) x_{n}=\alpha \int_{x_{n}}^{x_{n-1}}\left[y-x_{n}\right] d G(y)
$$

starting with $x_{0}=\bar{x} \cdot{ }^{16}$ Given this partition, note that $\delta=0$ and

$$
R(x)=x_{n}, R^{-1}(x)=x_{n-1} \text { for } x \in\left[x_{n}, x_{n-1}\right)
$$

\footnotetext{
${ }^{16}$ These matching sets are not closed. This is because the reservation fitness rules are not continuous across the class boundaries. Strictly speaking, the definition of the inverse function $R^{-1}($.$) requires the$ sup operator as the max does not exist. Strictly positive decay implies no such discontinuities and the matching sets are then closed.
} 
then solve the differential equation (7) above. The insight is that each single with $x \in$ $\left[x_{n}, x_{n-1}\right)$ enjoys the same acceptance set $A(x)=\left[0, x_{n-1}\right)$. No decay $(\delta=0)$ and equation (7) then imply each single in set $\left[x_{n}, x_{n-1}\right)$ has the same reservation fitness $R(x)=x_{n}<$ $x_{n-1}$. Optimality therefore implies those with fitness $x \in\left[x_{n}, x_{n-1}\right)$ propose to any agent with fitness $x^{\prime} \geq x_{n}$. But as they are only accepted by those with $x^{\prime}<x_{n-1}$, agents in $\left[x_{n}, x_{n-1}\right)$ form a class in that they only match with each other.

A critical feature of the class outcome is that the reservation fitness rule $R($.$) is not$ continuous across the class boundaries $x_{n}$. This cannot occur with positive decay $(\delta>0)$. Consider for example a class 1 single; i.e. one with fitness $x \in\left[x_{1}, x_{0}\right]$. With no decay, this single enjoys proposals from the entire line $[0, \bar{x}]$ in perpetuity, and so has constant reservation fitness $x_{1}$. But with decay, if this single remains unmatched, then at some finite date, fitness $x$ decays below $x_{1}$ and class 1 individuals no longer propose. Anticipating this event implies that the value of being single $V(x)$ and, hence, the reservation fitness $R($. fall as $x \rightarrow x_{1}$, thus breaking the class structure as identified in Burdett and Coles (1997). Instead, decay implies equilibrium matching sets as described in Figure 3. ${ }^{17}$

To understand this figure, consider the life cycle of a single initially endowed with $x=\bar{x}$. Let $\bar{R}$ denote his/her initial reservation fitness, $\bar{R}=R(\bar{x})$, where frictions and discounting ensure $\bar{R}<\bar{x}$. When entering the marriage market, a type $x=\bar{x}$ enjoys an acceptance set equal to the entire line - nobody can do better than match with the fittest type. But if he/she fails to find a suitable partner, fitness gradually declines and approaches $\bar{R}$. While fitness $x$ exceeds $\bar{R}$ the acceptance set remains the entire line. But once $x$ falls below $\bar{R}$, the acceptance set strictly shrinks with age. Anticipating this collapse in offers, the single becomes gradually less selective with age and as fitness $x \rightarrow 0$, the acceptance set $A(x) \rightarrow\{0\}$ and $R(x) \rightarrow 0$.

Note that $R^{-1}$ (.) is the rotation of $R($.$) around the 45$ degree line. A simple contradiction argument establishes that the matching set $M(x)=\left[R(x), R^{-1}(x)\right]$ is always non-empty. In fact, $x \in M(x)$ for all $x \in(0, \bar{x}] .{ }^{18}$ Conceptually, one might interpret the issue "does $x$ lie in $M(x)$ ?" as the question "would you marry yourself?". If $x \in M(x)$, the answer is "yes". As $x \in M(x)$ for all $x \in(0, \bar{x}]$, then random contacts implies there must be positive assortative matching; i.e., at the point of marriage, fitness is positively correlated across partners. To see why, consider two types with fitness $x^{H}>x^{L}>0$. If

\footnotetext{
${ }^{17}$ The values used to construct the figure will also be used (and discussed in detail) in the numerical exercise presented in Section 3. Here we simply notice that $\bar{x}=1$ and $\bar{R}=0.712$.

${ }^{18}$ If $x \notin M(x)$ then the marriage set $M(x)=\emptyset$. But an empty marriage set indicates that the single waits to become married. Discounting then implies that the single is better off with a lower fitness level, which is a contradiction.
} 
two $x^{H}$ types or two $x^{L}$ types meet, equilibrium implies they marry and exit the market. But if an $x^{L}$ and an $x^{H}$ meet, they may or may not marry. Given contacts are random, such sorting implies that fitness $x$ will be positively correlated across matched partners (Shimer and Smith 2000).

\subsection{Symmetric Career Options: $\lambda_{m}=\lambda_{f}>0$}

Recall that a match between a male $\left(x_{m}, t_{m}\right)$ and a female $\left(x_{f}, t_{f}\right)$ yields individual payoffs (3) and (4). Suppose that unsuccessful labour market participants become successful at rate $\lambda>0$, and this is the same for both sexes. For simplicity, we only consider symmetric equilibria where men and women use the same reservation match strategy $R($.$) .$

In a steady state, let $\pi_{t}$ denote the proportion of singles with success $t=L, H$, and let $G(. \mid t)$ denote the distribution of fitness across singles conditional on success $t$. For ease of exposition assume: ${ }^{19}$.

(A1) $G(. \mid t)$ contains no mass points and has connected support $(0, \bar{x}]$.

Let $P_{t_{m} t_{f}}\left(x_{m}\right) \subseteq[0, \bar{x}]$ denote the proposal set of a man of type $\left(x_{m}, t_{m}\right)$, i.e., male $\left(x_{m}, t_{m}\right)$ will propose to a woman of type $\left(x_{f}, t_{f}\right)$ if and only if her fitness $x_{f} \in P_{t_{m} t_{f}}\left(x_{m}\right)$. To illustrate, suppose that both are successful, $t_{m}=t_{f}=H$. The man will propose if and only if her fitness $x_{f} \in P_{H H}\left(x_{m}\right)$. Symmetry implies that the woman proposes if and only if $x_{m} \in P_{H H}\left(x_{f}\right)$ and a match is formed only if both propose. Note the first subscript refers to own success and the second to the success of the potential partner. A matching equilibrium requires proposal sets be optimal given all individuals use these proposal rules.

Definition of Matching Equilibrium:

For given $G$ satisfying (A1), a matching equilibrium is a set of proposal correspondences $\left\{P_{H H}(x), P_{H L}(x), P_{L H}(x), P_{L L}(x)\right\}$ for all $x \in(0, \bar{x}]$ where all propose according to these rules and $P_{t t^{\prime}}(x)$ is the optimal proposal set of any individual $(x, t)$.

As before we need to define acceptance sets. Consider an unsuccessful man $\left(x_{m}, L\right)$ and suppose he meets a successful woman $\left(x_{f}, H\right)$. She will propose to him as long as he is in her proposal set, i.e., if $x_{m} \in P_{H L}\left(x_{f}\right)$. Let $A_{L H}\left(x_{m}\right)$ denote the set of successful women who are willing to propose to $\left(x_{m}, L\right)$. Thus,

$$
A_{L H}\left(x_{m}\right)=\left\{x_{f} \in[0, \bar{x}]: x_{m} \in P_{H L}\left(x_{f}\right)\right\}
$$

describes the set of successful women who will accept $\left(x_{m}, L\right)$. More generally, let $A_{t_{m} t_{f}}\left(x_{m}\right) \subseteq$

\footnotetext{
${ }^{19}$ This restriction is automatically satisfied in any steady state with $\delta>0$
} 
$[0, \bar{x}]$ denote the acceptance set of a man of type $\left(x_{m}, t_{m}\right)$, that is,

$$
A_{t_{m} t_{f}}\left(x_{m}\right)=\left\{x_{f} \in[0, \bar{x}]: x_{m} \in P_{t_{f} t_{m}}\left(x_{f}\right)\right\}
$$

denotes the set of women with success $t_{f}$ who will propose to $\left(x_{m}, t_{m}\right)$. Again note that the first subscript in $A_{t_{m} t_{f}}\left(x_{m}\right)$ refers to own type, the second to the success of the contacted partner.

We now characterise the Bellman equations. Let $V_{H}(x)$ denote the value of being a successful single with fitness $x$. Over an arbitrarily small time period $\Delta>0$, the Bellman equation describing $V_{H}($.$) is$

$V_{H}(x)=e^{-(r+q) \Delta}\left\{\begin{array}{c}w^{H} \Delta+(1-\alpha \Delta) V_{H}\left(x e^{-\delta \Delta}\right)+o(\Delta) \\ +\alpha \Delta \sum_{t^{\prime}=L, H} \pi_{t^{\prime}}\left[\begin{array}{c}\int_{x^{\prime} \notin A_{H t^{\prime}}\left(x e^{-\delta \Delta}\right)} V_{H}\left(x e^{-\delta \Delta}\right) d G\left(x^{\prime} \mid t^{\prime}\right) \\ +\int_{x^{\prime} \in A_{H t^{\prime}}\left(x e^{-\delta \Delta}\right)} \max \left[x^{\prime}+W^{H}, V_{H}\left(x e^{-\delta \Delta}\right)\right] d G\left(x^{\prime} \mid t^{\prime}\right)\end{array}\right]\end{array}\right\}$.

Conditional on survival, a successful single $(x, H)$ enjoys flow payoff $w^{H}$ while single and the first (top) line in brackets describes the single's continuation payoff if no-one is contacted (our single remains unmatched with reduced fitness). The second line describes the payoff given contact with a single $\left(x^{\prime}, t^{\prime}\right)$ of the opposite sex, where the contacted single is either not willing to match $\left(x^{\prime} \notin A_{H t^{\prime}}\right)$ or is willing to match $\left(x^{\prime} \in A_{H t^{\prime}}\right)$ and our single then considers whether to propose (and obtain payoff $x^{\prime}+W^{H}$ ) or remain unmatched. The $o(\Delta)$ term reflects the Poisson approximation over the (small) time interval $\Delta$ and has the property that $o(\Delta) / \Delta \rightarrow 0$ as $\Delta \rightarrow 0$. Rearranging suitably and taking the limit as $\Delta \rightarrow 0$ yields the flow Bellman equation:

$$
(r+q) V_{H}(x)+\delta x V_{H}^{\prime}(x)=w^{H}+\alpha \sum_{t^{\prime}=L, H} \pi_{t^{\prime}} \int_{x^{\prime} \in A_{H t^{\prime}}(x)} \max \left[x^{\prime}+W^{H}-V_{H}(x), 0\right] d G\left(x^{\prime} \mid t^{\prime}\right) .
$$

As before, the left hand side describes the flow value of being unmatched where the agent's fitness falls at rate $\delta$. The right hand side describes the flow return, where $w^{H}$ is the flow payoff while single and the second term captures the probability our single contacts a single $\left(x^{\prime}, t^{\prime}\right)$ of the opposite sex who is willing to match and so potentially enjoys capital gain $x^{\prime}+W^{H}-V_{H}(x) \geq 0$.

The optimal proposal strategy in (10) implies reservation fitness rules

$$
R_{H H}(x)=V_{H}(x)-W^{H} ; R_{H L}(x)=V_{H}(x)-W^{H},
$$

where a single $(x, H)$ proposes to a single $\left(x^{\prime}, t^{\prime}\right)$ if and only if fitness $x^{\prime} \geq R_{H t^{\prime}}(x)$ with $t^{\prime} \in\{L, H\}$. Although these reservation rules are the same, notational clarity requires 
continuing to distinguish between contacts $t^{\prime}=L, H$. Thus the proposal sets for type $(x, H)$ are given by

$$
P_{H H}(x)=P_{H L}(x)=\left[R_{H L}(x), \bar{x}\right] .
$$

As $R_{H H}(x)=R_{H L}(x)$, the reservation fitness of a successful single does not depend on the success of the contacted partner. This occurs as we have assumed consumption payoff equal to $\max \left[W^{t_{m}}, W^{t_{f}}\right]$ and so marrying someone no more successful does not yield a lifestyle improvement.

Consider now $V_{L}(x)$ which denotes the value of being an unsuccessful single $(x, L)$ using an optimal proposal strategy. The argument used above leads to the following Bellman equation for $V_{L}$ :

$$
\begin{aligned}
(r+q) V_{L}(x)+\delta x V_{L}^{\prime}(x)= & w^{L}+\alpha \pi_{H} \int_{x^{\prime} \in A_{L H}(x)} \max \left[x^{\prime}+W^{H}-V_{L}(x), 0\right] d G\left(x^{\prime} \mid H\right) \\
& +\alpha \pi_{L} \int_{x^{\prime} \in A_{L L}(x)} \max \left[x^{\prime}+W^{L}-V_{L}(x), 0\right] d G\left(x^{\prime} \mid L\right) \\
& +\lambda\left[V_{H}(x)-V_{L}(x)\right] .
\end{aligned}
$$

The interpretation of (12) is the same as for (10), but being unsuccessful yields three differences: (i) the flow value of being single is only $w^{L}$, (ii) matching with another unsuccessful type only yields payoff $x^{\prime}+W^{L}$ and so unsuccessful types have a higher return to matching with someone successful, and (iii) there is an expected return to becoming successful (third line in the right-hand side of (12)).

The optimal proposal strategy of an unsuccessful single also has the reservation fitness property. Define the reservation fitness levels

$$
\begin{aligned}
R_{L H}(x) & =V_{L}(x)-W^{H} \\
R_{L L}(x) & =V_{L}(x)-W^{L},
\end{aligned}
$$

and note that an unsuccessful single $(x, L)$ proposes to a single $\left(x^{\prime}, t^{\prime}\right)$ if and only if that single's fitness $x^{\prime} \geq R_{L t^{\prime}}(x)$ with $t^{\prime} \in\{L, H\}$. Thus, the proposal sets for type $(x, L)$ are given by

$$
P_{L H}(x)=\left[R_{L H}(x), \bar{x}\right] \text { and } P_{L L}(x)=\left[R_{L L}(x), \bar{x}\right] .
$$

Unlike the successful types, the reservation fitness rules of unsuccessful singles falls onefor-one with the expected future lifetime earnings of the potential partner, i.e., $R_{L H}(x)-$ $R_{L L}(x)=-\left(W^{H}-W^{L}\right)$. Marrying someone more successful yields a lifestyle improvement; hence, to compensate, the single is willing to accept a lower fitness. 
The next step is to characterise the equilibrium acceptance sets. To do this we first establish that, in equilibrium, the value functions $V_{H}$ and $V_{L}$ are (weakly) increasing in $x$. This occurs because of the the reservation fitness property: if a single $\left(x^{\prime}, t^{\prime}\right)$ accepts $(x, t)$, then that same single accepts any $(y, t)$ with fitness $y>x$. Hence, type $(y, t)$ enjoys at least as good an acceptance set as agent $(x, t)$. Furthermore, should agents with fitness $x, y$ remain unmatched into the future, the agent with original fitness $y$ always has strictly greater fitness and so always enjoys a no-worse acceptance set than agent $x$. As each has the same promotion prospects, an agent with fitness $y$ can be no worse off than one who has fitness $x<y$, and so $V_{L}, V_{H}$ must be weakly increasing in fitness. We have therefore established the following property.

Equilibrium Property I: $V_{L}(),. V_{H}($.$) are non-decreasing in fitness x$, and hence the reservation fitness rules $R_{t t^{\prime}}($.$) are non decreasing in x$ for $t, t^{\prime} \in\{L, H\}$. Thus, agents with higher fitness $x$ are (weakly) more selective than agents with lower fitness $x$.

Given reservation fitness rules are non-decreasing in own fitness, define their inverse functions as follows:

$$
R_{t^{\prime} t}^{-1}(x)=\sup \left\{x^{\prime} \in[0, \bar{x}]: R_{t^{\prime} t}\left(x^{\prime}\right) \leq x\right\} .
$$

The inverse function $R_{t^{\prime} t}^{-1}(x)$ identifies the fittest type with success $t^{\prime}$ who might be willing to match with $(x, t)$. Equilibrium Property I then implies that all types $\left(x^{\prime}, t^{\prime}\right)$ with fitness satisfying $x^{\prime}<R_{t^{\prime} t}^{-1}(x)$ will propose to $(x, t)$, while by definition all those with fitness $x^{\prime}>R_{t^{\prime} t}^{-1}(x)$ will not propose to $(x, t)$. Hence we have established our second equilibrium property.

Equilibrium Property II: For $t, t^{\prime} \in\{L, H\}$, the acceptance set of a type $(x, t)$ is connected and either $A_{t t^{\prime}}(x)=\left[0, R_{t^{\prime} t}^{-1}(x)\right]$ or $A_{t t^{\prime}}(x)=\left[0, R_{t^{\prime} t}^{-1}(x)\right)$.

As $R_{t^{\prime} t}^{-1}(x)$ is defined as the supremum, rather than the maximum, we do not know whether $x^{\prime}=R_{t^{\prime} t}^{-1}(x)$ is willing to propose or not. This complication, however, plays no role since (A1) implies $G\left(. \mid t^{\prime}\right)$ contains no mass points. As $V_{H}$ and $V_{L}$ are given by the Bellman equations (10) and (12) respectively, we now have the following characterisation of a matching equilibrium.

Proposition 1A (Matching Equilibrium). Given any $G$ satisfying (A1), a Matching Equilibrium implies proposal sets $P_{t t^{\prime}}(x)=\left[R_{t t^{\prime}}(x), \bar{x}\right]$ where the reservation fitness rules 
$R_{t t^{\prime}}$ are given by (11) and (13), and $V_{H}$ and $V_{L}$ satisfy:

$$
\begin{aligned}
(r+q) V_{H}(x)+\delta x V_{H}^{\prime}(x)= & w^{H}+\alpha \pi_{H} \int_{R_{H H}(x)}^{R_{H H}^{-1}(x)}\left[x^{\prime}+W^{H}-V_{H}(x)\right] d G\left(x^{\prime} \mid H\right) \\
& +\alpha \pi_{L} \int_{R_{H L}(x)}^{R_{L H}^{-1}(x)}\left[x^{\prime}+W^{H}-V_{H}(x)\right] d G\left(x^{\prime} \mid L\right), \\
(r+q) V_{L}(x)+\delta x V_{L}^{\prime}(x)= & w^{L}+\alpha \pi^{H} \int_{R_{L H}(x)}^{R_{H L}^{-1}(x)}\left[x^{\prime}+W^{H}-V_{L}(x)\right] d G\left(x^{\prime} \mid H\right) \\
& +\alpha \pi_{L} \int_{R_{L L}}^{R_{L L}^{-1}(x)}\left[x^{\prime}+W^{L}-V_{L}(x)\right] d G\left(x^{\prime} \mid L\right) \\
& +\lambda\left[V_{H}(x)-V_{L}(x)\right],
\end{aligned}
$$

and $R_{t t^{\prime}}^{-1}($.$) are the inverse functions defined by (14).$

Identifying a Matching Equilibrium requires solving the following fixed point problem. Suppose arbitrary acceptance sets $A_{t t^{\prime}}(x)=\left[0, \widehat{A}_{t t^{\prime}}(x)\right]$ where $\widehat{A}_{t t^{\prime}}(x)$ are any nondecreasing functions satisfying $\widehat{A}_{t t^{\prime}}(x) \in[0, \bar{x}]$ for all $x \in[0, \bar{x}]$. The Bellman equations (10),(12) then yield $V_{L}, V_{H}$ and so (11),(13) yield the corresponding reservation fitness rules $R_{t t^{\prime}}(x)$. A Matching Equilibrium requires the assumed acceptance sets must be consistent with the implied reservation fitness rules $R_{t t^{\prime}}(x)$; i.e., $\widehat{A}_{t t^{\prime}}(x)$ must satisfy

$$
\widehat{A}_{t t^{\prime}}(x)=R_{t^{\prime} t}^{-1}(x) \text { for all } x \in[0, \bar{x}] \text { and } t, t^{\prime} \in\{L, H\} .
$$

This fixed point and its associated matching sets depend on $G$. $G$ is exogenous in a Matching Equilibrium but is endogenously determined in a Market Equilibrium which we now consider.

Let $h_{H}(x)$ denote the exit rate of a successful individual $(x, H)$ from being single. A Matching Equilibrium implies

$$
h_{H}(x)=q+\alpha \pi_{H} \int_{R_{H H}(x)}^{R_{H H}^{-1}(x)} d G\left(x^{\prime} \mid H\right)+\alpha\left(1-\pi_{H}\right) \int_{R_{H L}(x)}^{R_{L H}^{-1}(x)} d G\left(x^{\prime} \mid L\right),
$$

where exit occurs via death or marriage. Let $h_{L}(x)$ denote the exit rate of a unsuccessful individual $(x, L)$ from being single and unsuccessful. In this case, a Matching Equilibrium implies

$$
h_{L}(x)=q+\lambda+\alpha \pi_{H} \int_{R_{L H}(x)}^{R_{H L}^{-1}(x)} d G\left(x^{\prime} \mid H\right)+\alpha\left(1-\pi_{H}\right) \int_{R_{L L}(x)}^{R_{L L}^{-1}(x)} d G\left(x^{\prime} \mid L\right),
$$

where exit from this state also occurs if the worker becomes successful. A Market Equilibrium requires finding a $G$ whose implied exit flows from the singles market, in a Matching 
Equilibrium, equals the exogenous entry flows $(g, J)$ and so is consistent with a steady state. Theorem 1A describes a Market Equilibrium.

Theorem 1A (Market Equilibrium). A Market Equilibrium is a population of $N$ unmatched singles of each sex with type distribution $G$, where:

(i) given $G$, Proposition $1 \mathrm{~A}$ describes the equilibrium matching strategies and so determines the exit rates $h_{H}(),. h_{L}($.$) as described above;$

(ii) $G$ is given by:

$$
\pi_{H}=\frac{\lambda}{\lambda+\int_{0}^{\bar{x}} h_{H}\left(x^{\prime}\right) d G\left(x^{\prime} \mid H\right)}
$$

with conditional distributions $G(. \mid L), G(. \mid H)$ satisfying

$$
\begin{aligned}
\int_{x}^{\bar{x}} h_{L}\left(x^{\prime}\right) d G\left(x^{\prime} \mid L\right)+\delta x \frac{d G(x \mid L)}{d x} & =\frac{g}{\pi_{L} N}[1-J(x)] \\
\int_{x}^{\bar{x}} h_{H}\left(x^{\prime}\right) d G\left(x^{\prime} \mid H\right)+\delta x \frac{d G(x \mid H)}{d x} & =\frac{\pi_{L}}{\pi_{H}} \lambda[1-G(x \mid L)]
\end{aligned}
$$

(iii) $N$ is given by

$$
N=\frac{g}{\pi_{L}\left[\int_{0}^{\bar{x}} h_{L}\left(x^{\prime}\right) d G\left(x^{\prime} \mid L\right)\right]}
$$

Proof. For unsuccessful singles, steady state turnover implies that for each $x \in[0, \bar{x}]$ and over the next instant $\Delta>0$ :

$$
\pi_{L} N\left[\int_{x}^{\bar{x}} h_{L}\left(x^{\prime}\right) d G\left(x^{\prime} \mid L\right) \Delta+\left[G\left(x e^{\delta \Delta} \mid L\right)-G(x \mid L)\right]+o(\Delta)\right]=g[1-J(x)] \Delta
$$

as the left hand side describes the number of unsuccessful singles with fitness greater than $x$ who exit this state (either by rate $h_{L}$ or by decay) which, in a steady state, must equal the entry inflow. Similarly for successful singles, steady state requires

$$
\begin{gathered}
\pi_{H} N\left[\int_{x}^{\bar{x}} h_{H}\left(x^{\prime}\right) d G\left(x^{\prime} \mid H\right) \Delta+\left[G\left(x e^{\delta \Delta} \mid H\right)-G(x \mid H)\right]+o(\Delta)\right] \\
=\left(1-\pi_{H}\right) N[1-G(x \mid L)] \lambda \Delta
\end{gathered}
$$

as the number of successful singles with fitness greater than $x \in[0, \bar{x}]$ who flow out must equal the number who flow in from the pool of unsuccessful singles. The equations for $N$ and $\pi_{H}$ are obtained by putting $x=0$ in these equations (i.e., total outflows must equal total inflows), while for $x \in(0,1]$, the differential equations for $G(. \mid t)$ are obtained by rearranging appropriately and taking $\Delta \rightarrow 0$. This completes the proof of Theorem $1 \mathrm{~A}$. 
Characterising a Market Equilibrium requires solving jointly the differential equations for $G(),. V_{t}($.$) as defined in Proposition 1 \mathrm{~A}$ and Theorem 1A, and identifying the fixed point where acceptance sets are consistent with proposal sets. Section 3 below discusses such equilibria in detail. We next characterise the glass ceilings case, where women have no promotion prospects in the labour market.

\subsection{Glass Ceilings: $\lambda_{m}>0, \lambda_{f}=0$}

Suppose that men enjoy $\lambda_{m}=\lambda$, but $\lambda_{f}=0$ for women. A match between a male $\left(x_{m}, t_{m}\right)$ and female $\left(x_{f},.\right)$ yields payoffs

$$
\begin{aligned}
& \pi_{m}(.)=x_{f}+W^{t_{m}} \\
& \pi_{w}(.)=x_{m}+W^{t_{m}}
\end{aligned}
$$

where $t_{m} \in\{L, H\}$ describes the male partner's success (women stuck on $w^{L}$ would obtain lifetime earnings $w^{L} /(r+q)<W^{L}$ by remaining in the labour market). Let $G_{f}$ describe the distribution of fitness across single women, let $\pi_{H}$ denote the proportion of single men who are successful and let $G(. \mid t)$ denote the conditional fitness distributions for single men with $t=L, H$.

As the earnings dynamics are asymmetric, men and women now use different proposal strategies. Fortunately, however, the formal arguments used above still apply. Let $V_{f}(x)$ denote the value of being an unmatched female with fitness $x$ (where female wages $w^{L}$ are degenerate). Let $V_{H}(x)$ denote the value of being a successful male and $V_{L}(x)$ denote the value of being an unsuccessful male with fitness $x$. As in the previous section, sequential search with no recall implies that all agents use reservation fitness rules.

Consider a woman with fitness $x$. Let $R_{f H}(x)$ denote her reservation fitness should she contact a successful male, i.e., she will propose to male $\left(x^{\prime}, H\right)$ if and only if his fitness $x^{\prime} \geq R_{f H}(x)$. Let $R_{f L}(x)$ denote her reservation fitness if instead the contacted male is unsuccessful. Similarly, let $R_{H}(x)$ denote the reservation fitness of a successful man, i.e., he will propose to any woman with fitness $x^{\prime} \geq R_{H}(x)$ and let $R_{L}(x)$ denote the reservation fitness of an unsuccessful man.

As before the reservation fitness strategies imply fitter types enjoy larger acceptance sets and so can be no worse off. Thus, the value functions $V_{H}, V_{L}, V_{f}$ are non-decreasing functions of own fitness $x$. As fitter types are no worse off, this implies the reservation fitness rules are also non-decreasing functions of $x$. Define their inverse functions as:

$$
R_{f H}^{-1}(x)=\sup \left\{x^{\prime} \in[0, \bar{x}]: R_{f H}\left(x^{\prime}\right) \leq x\right\}
$$




$$
R_{f L}^{-1}(x)=\sup \left\{x^{\prime} \in[0, \bar{x}]: R_{f L}\left(x^{\prime}\right) \leq x\right\} .
$$

$R_{f H}^{-1}(x)$ identifies the fittest female who is willing to propose to a successful man with fitness $x$, and $\left[0, R_{f H}^{-1}(x)\right]$ identifies the equilibrium acceptance set of successful men with fitness $x$. Similarly $\left[0, R_{f L}^{-1}(x)\right]$ is the equilibrium acceptance set of unsuccessful men with fitness $x$. Moreover, define

$$
\begin{aligned}
& R_{H}^{-1}(x)=\sup \left\{x^{\prime} \in[0, \bar{x}]: R_{H}\left(x^{\prime}\right) \leq x\right\} \\
& R_{L}^{-1}(x)=\sup \left\{x^{\prime} \in[0, \bar{x}]: R_{L}\left(x^{\prime}\right) \leq x\right\}
\end{aligned}
$$

$R_{H}^{-1}(x)$, therefore, describes the fittest successful man who will propose to a woman with fitness $x$, and so her acceptance set among successful men is $\left[0, R_{H}^{-1}(x)\right]$. Similarly $\left[0, R_{L}^{-1}(x)\right]$ describes her acceptance set among unsuccessful men. Identifying a Matching Equilibrium requires solving the following fixed point problem. As the argument is the same as in the previous section, we omit a proof.

Proposition 1B (Matching Equilibrium with glass ceilings). A Matching Equilibrium implies reservation fitness rules

$$
\begin{aligned}
R_{f H}(x) & =V_{f}(x)-W^{H}, R_{f L}(x)=V_{f}(x)-W^{L} \\
R_{H}(x) & =V_{H}(x)-W^{H}, R_{L}(x)=V_{L}(x)-W^{L}
\end{aligned}
$$

where the value functions $V_{f}, V_{L}, V_{H}$ are given by:

$$
\begin{aligned}
(r+q) V_{f}(x)+\delta x \frac{d V_{f}}{d x}= & w^{L}+\alpha \pi_{H} \int_{R_{f H}(x)}^{R_{H}^{-1}(x)}\left[x^{\prime}+W^{H}-V_{f}(x)\right] d G\left(x^{\prime} \mid H\right) \\
& +\alpha\left(1-\pi_{H}\right) \int_{R_{f L}(x)}^{R_{L}^{-1}(x)}\left[x^{\prime}+W^{L}-V_{f}(x)\right] d G\left(x^{\prime} \mid L\right) \\
(r+q) V_{H}(x)+\delta x \frac{d V_{H}}{d x}= & w^{H}+\alpha \int_{R_{H}(x)}^{R_{f H}^{-1}(x)}\left[x^{\prime}+W^{H}-V_{H}(x)\right] d G_{f}\left(x^{\prime}\right) \\
(r+q) V_{L}(x)+\delta x \frac{d V_{L}}{d x}= & w^{L}+\alpha \int_{R_{L}(x)}^{R_{f L}^{-1}(x)}\left[x^{\prime}+W^{L}-V_{L}(x)\right] d G_{f}\left(x^{\prime}\right) \\
& +\lambda\left[V_{H}(x)-V_{L}(x)\right]
\end{aligned}
$$

and the inverse functions are defined in the text.

The structure of the Bellman equations is the same as before: the flow value of being unmatched equals current earnings plus the expected gain by meeting a partner who is 
willing to marry. The reservation fitness rules are identified where the single is indifferent to proposing or remaining unmatched. Identifying a matching equilibrium requires finding acceptance sets whose supremum is consistent with the inverse of the resulting reservation fitness rules.

As before the equilibrium matching sets depend on the type distributions $G_{s}$ which are endogenously determined in a Market Equilibrium. To identify a Market Equilibrium, note that a Matching Equilibrium implies the following exit rates. First, the exit rate of a man from being single and unsuccessful is

$$
h_{L}(x)=q+\lambda+\alpha \int_{R_{L}(x)}^{R_{f L}^{-1}(x)} d G_{f}\left(x^{\prime}\right)
$$

where $\lambda$ is his promotion rate to being successful. Second, the exit rate of a man from being single and successful is

$$
h_{H}(x)=q+\alpha \int_{R_{H}(x)}^{\left[R_{f H}^{-1}(x)\right.} d G_{f}\left(x^{\prime}\right)
$$

Third, the exit rate of a woman from being single is

$$
h_{f}(x)=q+\alpha \pi_{H} \int_{R_{f H}(x)}^{R_{H}^{-1}(x)} d G\left(x^{\prime} \mid H\right)+\alpha\left(1-\pi_{H}\right) \int_{R_{f L}(x)}^{R_{L}^{-1}(x)} d G\left(x^{\prime} \mid L\right) .
$$

We can now describe the conditions for a Market Equilibrium.

Theorem 1B (Market Equilibrium with glass ceilings). A Market Equilibrium implies:

(i) equilibrium matching strategies as described in Proposition 1B and hence exit rates as described above;

(ii) distribution of female fitness $G_{f}($.$) given by$

$$
\int_{x}^{\bar{x}} h_{f}\left(x^{\prime}\right) d G_{f}\left(x^{\prime}\right)+\delta x \frac{d G_{f}}{d x}=\frac{g}{N}[1-J(x)]
$$

(iii) proportion $\pi_{H}$ of single men who are successful given by

$$
\pi_{H}=\frac{\lambda}{\lambda+\int_{0}^{\bar{x}} h_{H}\left(x^{\prime}\right) d G\left(x^{\prime} \mid H\right)}
$$

and conditional fitness distributions given by:

$$
\begin{aligned}
\int_{x}^{\bar{x}} h_{L}\left(x^{\prime}\right) d G\left(x^{\prime} \mid L\right)+\delta x \frac{d G(x \mid L)}{d x} & =\frac{g}{\left(1-\pi_{H}\right) N}[1-J(x)] \\
\int_{x}^{\bar{x}} h_{H}\left(x^{\prime}\right) d G\left(x^{\prime} \mid H\right)+\delta x \frac{d G(x \mid H)}{d x} & =\frac{1-\pi_{H}}{\pi_{H}} \lambda[1-G(x \mid L)]
\end{aligned}
$$


with $N$ given by

$$
N=\frac{g}{\int_{0}^{\bar{x}} h_{f}\left(x^{\prime}\right) d G_{f}\left(x^{\prime}\right)}
$$

We omit the proof because the argument and the structure of these equations is the same as those of Theorem 1A. Characterising a Market Equilibrium again requires solving jointly the differential equations for the distribution functions and the value functions along with the fixed point problem that the acceptance sets are consistent with the reservation fitness rules.

\section{Discussion with a Numerical Example}

The equations describing the Market Equilibrium are too complicated to solve analytically but are straightforward to solve computationally. We therefore illustrate the discussion using a numerical example. The insights that follow are robust to the choice of numbers, but we choose numbers which generate reasonable outcomes.

First normalise $\bar{x}=1$ and assume that all men and women enter the marriage market with $x=\bar{x}=1$. Suppose further that all enter the marriage market at age 20, which then implies fitness and age are synonymous; i.e., fitness $x=\exp \{-\delta($ age -20$)\}$. We assume fitness has a half-life of 20 years. Using a year as the reference unit of time, this requires annual depreciation rate $\delta=0.035$ and the relationship between fitness and age as in Table 1.

Assume exit rate $q=0.025$, so that the expected life (in the marriage market) is 40 years. The discount rate, $r$, is 0.015 so that the gross discount rate $(r+q)$ is 4 percent per year. We set $\lambda=0.015$. If all men and women participated in the labour market then, together with $q=0.025$, steady state would imply 37.5 percent of all workers are successful. This value of $\lambda$ also means that the probability that an individual is successful before age 40 is around $1 / 4$. Thus, being successful in the labour market is not uncommon, but it is rare among the young.

We choose wage rates so that $W^{H}=0.5$ and $W^{L}=0.25$; therefore, becoming successful is equivalent to doubling one's expected lifetime earnings. The difference $W^{H}-W^{L}=0.25$ represents the utility premium that an unsuccessful type obtains by matching with a successful, rather than another unsuccessful, type. The implied wage rates are $w^{H}=0.02$ and $w^{L}=0.00625$. Hence, a currently unsuccessful worker anticipates an annual wage growth $\lambda\left(w^{H}-w^{L}\right) / w_{L}$ of 3.3 percent. Finally, we set $\alpha=0.25$, and so the expected time 
between contacts is 4 years. The interpretation is not that this is the time taken to meet anyone of the opposite sex. Rather, it is the time taken to find someone with whom one is mutually compatible and so might consider forming a life partnership. Note that $\alpha / q=10$ implies a single, on average, might consider marriage with 10 prospective partners over a lifetime.

Consider first the symmetric career options case with $\lambda_{m}=\lambda_{f}=\lambda$. With the above parameter values, a Market Equilibrium implies $\pi_{H}=0.08$ : the marriage market is largely filled with young, currently unsuccessful singles. Figure 4 describes the matching set of unsuccessful singles $\left[R_{L L}(x), R_{L L}^{-1}(x)\right]$ in a Market Equilibrium. As most singles in the market are young and unsuccessful, and the transition to success is relatively slow, the equilibrium matching structure is very similar to Figure 3 with no income dynamics (Figure 3 in fact describes the matching sets for the above parameter values and $\lambda=0$ ). An important theoretical insight, however, is that the matching set is empty for unsuccessful types with sufficiently low fitness $(x<0.03$ in this case). This occurs as the possibility of becoming successful tomorrow, and so attracting a fitter partner, raises the option value of deferring getting married. This option effect plays a key role in the glass ceilings case discussed below. Here in a symmetric labour market, the acceptance set of the unfit and unsuccessful is sufficiently poor that these types defer getting married until they become successful and can then attract a much fitter (though unsuccessful) partner.

The key advantage of becoming successful is that it considerably increases the acceptance set with unsuccessful types. Figure 5 plots the matching set of successful types with unsuccessful types, $\left[R_{H L}(x), R_{L H}^{-1}(x)\right]$. Relative to the acceptance correspondence $\left[0, R_{L L}^{-1}\right]$ in Figure 4 for an unsuccessful type, the acceptance correspondence for successful types, $\left[0, R_{L H}^{-1}\right]$, shifts to the left by the amount $W^{H}-W^{L}=0.25$. Becoming successful implies a large increase in the acceptance set. For example, given contact with an unsuccessful single, an unsuccessful 40 year old has an acceptance set $A_{L L}(x)=[0,0.72]$ which contains relatively few singles (most singles are younger than 30 and so lie outside this set). Conversely, a successful 40 year old enjoys an acceptance set $A_{H L}(x)$ equal to the entire line. As most singles are unsuccessful in a Market Equilibrium $\left(\pi_{H}=0.08\right)$, becoming successful yields a large improvement in marriage prospects.

Note that successful types between ages 29 and 42 will not "marry themselves", that is, their reservation match $R_{H H}(x)>x$. As fitness and age are synonymous in this example, their reservation 'age' is below their own 'age'; each instead will only marry someone who is sufficiently young. Toyboyism arises as an equilibrium outcome, where successful types approaching middle age match with younger unsuccessful types. This outcome reflects the 
submodular payoff structure described earlier. The marginal value of marrying someone successful is decreasing in own success. The extreme case considered here implies that, once successful, the success of the potential partner is immaterial to the proposal decision. Instead, the successful prefer fitter types. Of course, being successful implies fitter and less successful types lie in their acceptance set.

Now consider the glass ceilings case where instead $\lambda_{f}=0$. A Market Equilibrium again implies that most singles in the marriage market are young, and $\pi_{H}=0.075$ also indicates that most single men are currently unsuccessful. Thus, most matches are between the young and currently unsuccessful. But the asymmetric career structure generates an age differential between married partners by gender. Figure 6 depicts the reservation fitness rules of unsuccessful men $\left(R_{L}\right)$ and of women given contact with an unsuccessful man $\left(R_{f L}\right)$. The relevant acceptance correspondences, $R_{L}^{-1}$ for women and $R_{f L}^{-1}$ for unsuccessful men, are identified by rotating these reservation fitness functions around the 45 degree line. A central result is that women have lower reservation fitness rules than unsuccessful men and, therefore, are less selective. This results in young women marrying more quickly than young men, and so it implies women tend to be younger than their male partners. There are three reasons for this gap in the reservation fitness rules.

First, consider (21) in Proposition 1B describing $V_{L}$. The reservation fitness rules implies that the reservation match of an unsuccessful man, $R_{L}$, evolves according to:

$$
(r+q) R_{L}(x)+\delta x \frac{d R_{L}}{d x}=\lambda\left[R_{H}(x)-R_{L}(x)\right]+\alpha \int_{R_{L}(x)}^{R_{f L}^{-1}(x)}\left[x^{\prime}-R_{L}(x)\right] d G_{f}\left(x^{\prime}\right)
$$

The first term on the right hand side of (24) is positive which, by increasing the return to staying single, raises the reservation fitness rule of unsuccessful men. This term reflects the possibility of becoming successful in the future, which occurs at rate $\lambda$. In the marriage market, becoming successful implies a larger acceptance set, and this makes the single better off (in addition to enjoying a wealthier lifestyle). The larger acceptance set then leads successful types to be pickier, which explains $R_{H}(x)-R_{L}(x)>0$. But the promotion effect $\lambda>0$ makes unsuccessful types pickier today. The possibility of becoming successful tomorrow, and so attracting a fitter bride, raises the option value of deferring marriage. This option therefore raises the reservation fitness rule of unsuccessful men and so men become more selective.

Second, consider (19) in Proposition 1B describing $V_{f}$. The reservation fitness rules 
imply $R_{f L}$ evolves according to ${ }^{20}$

$$
(r+q) R_{f L}(x)+\delta x \frac{d R_{f L}}{d x}=-\lambda\left[W^{H}-W^{L}\right]+\alpha \sum_{t^{\prime}=L, H} \pi_{t^{\prime}} \int_{R_{f t^{\prime}}(x)}^{R_{t^{\prime}}^{-1}(x)}\left[x^{\prime}-R_{f t^{\prime}}(x)\right] d G\left(x^{\prime} \mid t^{\prime}\right)
$$

In contrast to (24), the first term on the right hand side of (25) is negative which therefore lowers the reservation fitness rule of women. Being stuck on low wages reduces a woman's return to remaining in the labour market. But by marrying an unsuccessful man, she shares his option of becoming successful in the future: thus, at rate $\lambda$, she and her partner will enjoy a wealth gain of $\left(W^{H}-W^{L}\right)$. This shared option reduces her return to remaining single and so lowers her reservation fitness level. Clearly, her reservation fitness is still lower given contact with a successful man, $R_{f H}=R_{F L}-\left(W^{H}-W^{L}\right)$.

Third, there is also an equilibrium feedback effect. Because (unsuccessful) men are more selective, women face smaller acceptance sets which reduce the return to remaining single and lower still further the reservation fitness rules of women. The converse holds for men, and this equilibrium feedback increases further the gap between their reservation fitness rules. ${ }^{21}$

Figure 7 describes the corresponding fitness densities in a Market Equilibrium. Most single men are unsuccessful $\left(\pi_{H}=0.075\right)$ and most singles are young (under 30). Young women have particularly high marriage rates (they are very likely to accept their first proposal) and so most marriages occur between young unsuccessful men and young women. There is an "old maid" effect (sufficiently old women never marry) which results in a second peak in $G_{f}^{\prime}($.$) at long ages (low fitness). { }^{22}$ The density of single successful men peaks at around age 26 but has a fat left tail. Successful men do not remain single for very long (yielding low $\pi_{H}=0.075$ ) and are likely to have significantly younger brides.

Figure 8 plots marriage rates by age, gender and success in a Market Equilibrium. The absence of career options for women implies that women have lower reservation fitness rules than men and so young women marry more quickly than young men. In a Market Equilibrium, a single woman finds that her arrival rate of proposals collapses once she reaches age 29 (i.e., when her fitness falls below $\bar{R}_{L}$ ). At age 40 , her marriage rate is only 0.04 (where $1 / 0.04$ is 25 years) and her marriage rate is zero once over 70 years. The

\footnotetext{
${ }^{20}$ Deriving this expression requires $(r+q) W^{L}=w^{L}+\lambda\left(W^{H}-W^{L}\right)$.

${ }^{21}$ This suggests that multiple (asymmetric) market equilibria might occur for some entry distributions $J$.

${ }^{22}$ The positive death rate ensures there is no mass of single females at fitness $x=0$. It can be shown that the density $G_{f}^{\prime}(x) \rightarrow g_{0} x^{b}$ where $b=-1+(q / \delta)$. For $q<\delta$ then, $G^{\prime}$ becomes arbitrarily large as $x \rightarrow 0$. However, $b>-1$ implies $G(x) \rightarrow 0$ as $x \rightarrow 0$ and so the number of agents with fitness less than $x$ becomes arbitrarily small, even though the density becomes unboundedly large.
} 
marriage hazard for unsuccessful men also plummets around age 30. But the possibility of becoming successful implies that they remain relatively desirable in the marriage market, and so their acceptance correspondence does not fall as quickly with age as it does for women. Of course, becoming successful leads to a large increase in the acceptance set, and marriage hazards plummet for successful men only once they reach age 43.

\section{Some Supporting Evidence}

A central premise of our model is that female marriage strategies have changed as female career opportunities have improved over time. Our theoretical framework provides two basic insights which we examine in this section. Specifically:

(i) Toyboys are an equilibrium matching outcome for women who are successful in the labour market. As becoming successful takes time, a woman may prefer a fitter (younger) male partner but, to be in her acceptance set, he will be relatively unsuccessful.

(ii) Career options raise the option value of deferring marriage. Becoming successful in the labour market improves one's "desirability", and successful types then enjoy a better pick from the pool of potential partners.

In what follows we provide some evidence in support of each of these implications, starting with the first. Our two data sources for Britain are the ONS Longitudinal Study (LS) and the British Household Panel Survey (BHPS), while our data source for the United States is the Integrated Public Use Microdata Series (IPUMS) of the Census micro data. The LS and IPUMS data are used to describe the characteristics of women who are partnered to toyboys, drawing attention to the changes observed between 1971 and 2001 for Britain and between 1950 and 2000 for the United States. The BHPS data, instead, are used to estimate the duration to first union and partners' joint age distribution at first partnership.

\subsection{Toyboys}

The LS contains individual-level information records from the 1971 Census of Population linked to information from the 1981, 1991, and 2001 censuses, together with vital events (e.g., births, deaths, and cancer registrations) for 1 percent of the population of England and Wales, comprising about 500,000 individuals at any one census. New LS member enter the study through birth or immigration. Although the longitudinal component of the data refers only to LS members, data for all the individuals living in the same household as 
an LS member are also included. This feature therefore allows us to identify women and their partners at each of the census years. For both partners, we have information on key demographic variables (e.g., age, ethnicity, and number of children) and socio-economic characteristics (e.g., highest educational attainments, working status, and occupation). ${ }^{23}$ Samples include only couples in which the woman is aged less than 60 at any census year and who are not residing in institutional group quarters (e.g., prisons or mental health institutions).

Our first task is to examine the characteristics of women who marry toyboys. Table 2 reports probit estimates by census year and their corresponding robust $t$-statistics (in absolute value) in parentheses. The dependent variable takes value one if the woman is at least five years older than her male partner, and zero otherwise. To ease interpretation, the estimates are expressed as marginal effects, which should be added to or subtracted from the baseline probabilities evaluated at the sample mean of all the variables included in estimation (first row). The estimates show that a woman's education and, especially, occupation are positively associated with her probability of being married to a toyboy. For instance, in 2001, a woman in a managerial job is 0.8 percentage points more likely to form a union with a man who is five years younger than another woman who has an unskilled job. This effect is large, representing a 12 percent increase in the baseline probability. ${ }^{24}$ Although the effect of female education has remained fairly stable over time, it has lost significance by 2001, and the part played by female occupation has become relatively more substantial.

But the strongest positive influences on the probability that a woman is married to a toyboy come from her education and occupation relative to her partner's. In 2001, a woman who has a university degree and is married to a man who does not is 1.3 percentage points more likely to be matched to a younger partner than a woman who is less educated than her husband. Similarly, a woman in a better occupation is almost 2 percentage points more likely to be married to a younger husband. The combination of these two effects is huge: a woman who is more educated and has a better occupation than her partner has a 45 percent higher probability to be observed in a toyboy couple than the average woman in the sample. Interestingly, the magnitudes of such effects (especially that related to occupation) have grown over time. Toyboyism, therefore, seems to emerge more strongly in recent years when women have greater options of a career (Goldin 2006).

\footnotetext{
${ }^{23}$ More information on the LS dataset is available at <http://www.celsius.lshtm.ac.uk/>.

${ }^{24}$ Conversely, male education and occupation are, in general, either uncorrelated or negatively correlated to the probability of observing toyboy couples. This is in line with the simulations in Figure 4, whereby successful women do not match with successful men.
} 
We also performed the same analysis with the occupation and education variables interacted with the woman's age. The results from these regressions (not shown for brevity) indicate that the effect of a woman having a higher-status occupation than her partner has increased over time across all age groups, but especially among women aged 30 to 40 . A similar pattern emerge for the relative effect of education. These (and the previous) results are consistent with the notion that women who are successful in the labour market are more likely to match with younger partners who are not as successful.

We repeated the same exercise for the United States, using data from the 1 percent IPUMS of the decennial censuses from 1960 to 2000 (Ruggles et al. 2004). Our 1980, 1990 and 2000 samples are from 1980 and 1990 IPUMS 1 percent "Metro" samples and the 2000 IPUMS 1 percent "Census" sample, respectively. These are 1-in-100 national random samples of the population, and are comparable over time as well as with the previous IPUMS 1 percent samples for 1960 and 1970. To keep comparability with the LS analysis, samples are restricted to couples who do not reside in institutional group quarters and in which the wife is aged less than 60 at any census year. Sample weights are used in all calculations. ${ }^{25}$ When we use the same specifications and variables used with the LS data, the results are remarkably similar to those shown earlier for Britain.

One advantage of the U.S. data, however, is that they contain information on total personal income as well as wage and salary income. In the context of our model, income can be seen as an alternative proxy of success. Thus, we performed again the previous analysis after replacing occupation with income. ${ }^{26}$ The results from this analysis are in Table 3 , which shows only the marginal effects of the variable indicating that the wife is more educated than her partner and of the variable indicating that she has a greater total income. Since 1970, the likelihood of observing a toyboy couple is approximately 1 percentage point higher if the woman has a greater income. Over the entire fifty-year period, this likelihood increases by an extra 0.5-1.2 percentage points if, in addition, she is also more educated. The income effect alone represents an increase in the baseline probability of about 2030 percent. The joint effects of both income and education, therefore, are substantial. We repeated the same exercise using labour income rather than total income, and found qualitatively similar results. Because income can be measured with error, we also estimated

\footnotetext{
${ }^{25}$ More information on the U.S. census microdata is available at $<$ http://www.ipums.org/ $>$.

${ }^{26}$ The IPUMS variables are INCTOT for total personal income and INCWAGE for wage and salary income. These two variables have been collected since the 1960 census. In the 1950 sample, they are available only for sample-line persons, while in the 1940 sample only INCWAGE is available. No income information was collected before. All income figures are deflated using the consumer price index (CPI) All Urban Consumers series CUUR0000SA0.
} 
an alternative specification in which the wife is defined to have a greater income only if her income exceeds that of her partner by at least 10 percent. ${ }^{27}$ The estimates from this analysis were virtually identical to those presented in Table 3. Such results, therefore, are quite robust: toyboy couples are more likely to be seen when the wife has a greater economic power relative to her male partner.

\subsection{Matching on Age at First Partnership}

Our second task is to analyze the age of women and men at the time of their first live-in partnership (marriage or cohabitation). For this purpose, we use data from the marital history files of the BHPS collected in the second wave of the survey (1992) and the panel marital information gathered over the period 1991-2003. ${ }^{28}$

Figure 2 in the Introduction plots the estimated hazard rates of entry into first partnership by age and sex for a sample of 4,856 couples for which we have complete information on their marital histories. These are based on maximum likelihood estimates of transition rates to marriage and cohabitation, which are assumed to be piecewise constant by single year of age. The survivor function implied by these estimates is the Kaplan-Meier, or product limit, estimator (Lancaster 1990).

From Figure 2 it is clear that women, on average, marry earlier than men. For example, by age 26 , about 70 percent of women and 50 percent of men had formed a union. The predicted mean age at first partnership is 24.3 years for women, almost 2 years earlier than that estimated for men. These figures compare well with existing studies of union formation in Britain (e.g., Berrington and Diamond 2000; Ermisch and Francesconi 2000), but are lower than those reported in official statistics, because the latter estimates are based on data that exclude cohabitations (Office for National Statistics 2006).

When individuals in the sample are stratified on birth cohort, we find evidence that later cohorts are postponing partnerships more (the results are not reported for convenience). For instance, the proportion of women who have ever had a partnership has declined in the latest cohorts: 75 percent of women born in the 1950-1955 cohort had formed their first union by the age of 24 years, but this had declined to 55 percent for the 1970-1975

\footnotetext{
${ }^{27}$ Of course, if both male and female incomes are affected by comparable measurement problems, there may not be any measurement error issue.

${ }^{28}$ Since Autumn 1991, the BHPS has annually interviewed a representative sample of about 5,500 households covering more than 10,000 individuals. The households from the European Community Household Panel subsample (followed between 1997 and 2001), those from the Scottish and Welsh booster samples (added to the BHPS in the ninth wave in 1999) and those from the Northern Ireland sample (which started in wave 11) are excluded from this analysis. Detailed information on the BHPS can be obtained at <http://www.iser.essex.ac.uk/ulsc/bhps/doc/>.
} 
cohort. This translates into a rise in women's median age at first partnership of 2 years between those two cohorts, from 21.3 years to 23.4 years. Postponement among men is also evident but not as large as in the case of women. Although the age difference between the sexes at first partnership still remains, it has declined quite markedly.

It is worth comparing Figure 2, describing actual hazard rates, against Figure 8 which describes the hazard rates implied by the glass ceilings case. The peak in the female hazard rate in Figure 8 occurs precisely when female fitness falls below the reservation fitness of the most eligible male singles. In the context of the model, Figure 2 suggests that women are sexually omnipotent until age 24 but their marital options decline thereafter. Figure 8 describes two hazard rates for men depending on whether they are successful or not. The average hazard rate has a peak significantly later than the female peak, reflecting that older but successful men remain highly desirable.

Giolito (2004) describes a related matching model with differential ageing across sexes but no career options for women. Specifically, it assumes that fecundity declines with age, that fecundity declines more quickly for women, and that only fecundity matters in the matching decision. As in Siow (1998), differential fecundity leads to gender age differences in the hazard rates to first partnership. Since the menopause typically occurs when women are in their forties, this model implies that women remain highly desirable through their thirties. The numerical example in Giolito (2004) predicts that female first partnership hazard rates peak at around age 40. This seems much too late for the data, with Figure 2 showing that the actual peak occurs between ages 24 and 26. This does not mean that single women in their mid-thirties are unconcerned about their ticking biological clocks. But it appears unlikely that differential fecundity by itself will be able to explain why female hazard rates peak at such a young age.

A different perspective is obtained by considering the age distribution of partners. Using the BHPS data on first partnerships, Figure 9 plots the joint age distribution of husbands and wives at the time they married. Confirming other existing demographic evidence (e.g., Schoen and Canudas-Romo 2005), men are older than their wives on average over the entire age range. Notice, however, that the distribution is more compressed up to age 24 of the wife and after age 39. It is widest between ages 24 and 38: the age dispersion (measured by the $90-10$ percentile gap) in the $24-38$ age range is almost 50 percent larger than the dispersion observed at either earlier or later ages. The model is reasonably consistent with this dispersion effect for two reasons. After age 24, single women are forced to become less picky and so more likely to marry substantially older men. Furthermore, the singles' market rapidly thins by age (see Figure 7 ). The lower meeting rate of potential partners 
(in the appropriate age range) yields even lower reservation match values and hence greater dispersion in age across matched partners. Also as career success is likely to be determined after age 24, career success heterogeneity provides an additional source of variation in observed partner ages. A puzzle, however, is explaining the fall in dispersion after age 38. Female menopause is not far from that age, but it is not obvious why the imminence of menopause should imply that ages are more tightly correlated across matched partners. It might, instead, reflect unobserved heterogeneity: the majority of first marriages occur when singles are in their twenties, and there are only relatively few first marriages where the woman is 40 or older. Such women might be special and explaining their marital behaviour is an interesting puzzle which is left for future research.

Repeating this exercise after distinguishing partnerships formed before 1990 from partnerships formed after 1990, we observe an even wider dispersion amongst more recent partnerships. These findings tie in well with Goldin's (2006) notion of "quiet revolution" in female employment. Better career options for women are leading to changes in marital strategies. As women have greater chances of being successful in the labour market, they tend to defer marriage and potentially match with someone younger.

\section{Conclusion}

This paper develops an equilibrium search model which explains the growing toyboy phenomenon. The data show that a woman who is more educated and has a better occupation than her partner has a 45 percent higher probability to be observed in a toyboy couple than the average woman in the sample. The magnitudes of such effects (especially that related to occupation) have grown over time. Similar results emerge when we consider income, rather than occupation.

Using a search framework with ageing and uncertain careers, we show that toyboy partnerships are an equilibrium outcome with (i) incomplete marriage contracts and (ii) preferences which are submodular in wealth. Arguably, both assumptions are quite natural: the former implies that couples do not contract on the terms of trade when forming the match, the latter entails that it is always better to marry someone rich but the marginal value of doing so is greatest for someone poor. The explanation of toyboys is that being a high wage earner makes one a more attractive match. Submodular payoffs in wealth implies a high earner has a relatively stronger preference to marry someone fit, while someone fit but poor has a relatively stronger preference to marry someone rich. As becoming successful takes time and fitness decays over time, such preferences explain why, 
historically, successful (older) men have married fitter (younger) wives. As women enjoy more equal opportunities in the labour market, successful (older) women now also enjoy fitter (younger) partners.

There are several avenues for further research. More work can be done to disaggregate the overall average hazard rates of singles as depicted in Figure 2. In the data we observe that average female hazard rates peak at around age 24 while average male hazard rates peak at age 28. We have argued that the differential fecundity approach, by itself, cannot explain such an early peak in female marriage hazard rates. Preliminary analyses, which distinguish individuals with higher educational qualifications from individuals with lower educational qualifications, show that the estimated hazard rates for better educated men and women are much closer to each other than those estimated for less educated people. This extension can then assess by how much the observed gender age differential between partners is due to women having historically lower rates of higher education, and thus unequal access to high-flying careers.

Ruling divorce out is a useful simplifying assumption. With no divorce, marriage gives a woman an equal claim on her partner's future success. Allowing divorce introduces additional time consistency issues: divorce potentially enables someone who has become successful to swap their original partner for a younger version. Also the threat of divorce can affect the negotiated terms of trade within the marriage. A number of studies analyse the value of trust in long term marriage partnerships (Cornelius 2003; Burdett et al. 2004; Eeckhout 2006; Masters 2006). Optimal divorce settlements would seemingly internalise the cost of divorce on the deserting partner (Chiappori and Weiss 2006). But how such settlements interact with incomplete marriage contracts (no contracting on the terms of trade) is an interesting issue which is left for future research. 


\section{References}

[1] Aiyagari, S. Rao, Jeremy Greenwood, and Nezih Guner. 2000. "On the State of the Union" Journal of Political Economy 108 (April): 213-44.

[2] Atakan, Alp E. 2006. "Assortative Matching with Explicit Search Costs" Econometrica 74 (May): 667-80.

[3] Bergstrom, Theodore C., and Mark Bagnoli. 1993. "Courtship as a Waiting Game." Journal of Political Economy 101 (February): 185-202.

[4] Berrington, Ann, and Ian Diamond. 2000. "Marriage of Cohabitation: A Competing Risks Analysis of First-Partnership Formation among the 1958 British Birth Cohort." Journal of the Royal Statistical Society Series A 163(2): 127-51.

[5] Bloch, Francis, and Harl Ryder. 2000. "Two Sided Search, Marriages and Matchmakers." International Economic Review 41 (February): 93-115.

[6] Blossfeld, Hans-Peter, and Catherine Hakim (eds.). 1997. Between Equalization and Marginalization: Women Working Part-Time in Europe and the United States of America Oxford: Oxford University Press.

[7] Booth, Alison L., and Melvyn G. Coles. 2006. "Education, Marriage and the Allocative Value of Romance." Manuscript, University of Essex.

[8] Burdett, Kenneth, and Melvyn G. Coles. 1997. "Marriage and Class." Quarterly Journal of Economics 112 (February): 141-68.

[9] Burdett, Kenneth, and Melvyn G. Coles. 1999. "Long-Term Partnership Formation: Marriage and Employment." Economic Journal 109 (June): F307-F334.

[10] Burdett, Kenneth, Ryoichi Imai, and Randall Wright. 2004. "Unstable Relationships." Frontiers of Macroeconomics 1 (1): 1-42.

[11] Burdett, Kenneth, and Randall Wright. 1998. "Two Sided Search." Review of Economic Dynamics 1 (January): 220-45.

[12] Casterline, John B., Lindy Williams, and Peter McDonald. 1986. "The Age Difference between Spouses: Variations among Developing Countries." Population Studies 40 (November): 353-74. 
[13] Chade, Hector. 2001. "Two-Sided Search and Perfect Segregation with Fixed Search Costs" Mathematical Social Sciences 42 (January): 31-51.

[14] Chade, Hector, and Gustavo Ventura. 2002. "Taxes and Marriage: A Two Sided Search Analysis." International Economic Review 43 (August): 955-85.

[15] Chiappori, Pierre-André, and Yoram Weiss. 2006. "Divorce, Remarriage and Welfare: A General Equilibrium Approach." Journal of the European Economic Association 4 (April-May): 415-26.

[16] Choo, Eugene, and Aloysius Siow. 2006. "Who Marries Whom and Why." Journal of Political Economy 114 (February): 175-201.

[17] Cole, Harold L., Goerge J. Mailath, and Andrew Postlewaite. 2001. "Efficient NonContractible Investments in Large Economies." Journal of Economic Theory 101 (December) 333-73.

[18] Cornelius, Tracy J. 2003. "A Search Model of Marriage and Divorce." Review of Economic Dynamics 6 (January): 135-55.

[19] Dixon, R. B. 1971. "Explaining Cross-Cultural Variations in Age at Marriage and Proportions never Marrying." Population Studies 25 (July): 215-33.

[20] Eeckhout, Jan. 1999. "Bilateral Search and Vertical Heterogeneity." International Economic Review 40 (November): 869-87.

[21] Eeckhout, Jan. 2006. "Minorities and Endogenous Segregation." Review of Economic Studies 73 (January): 31-53.

[22] Ermisch, John E., and Marco Francesconi. 2000. "Cohabitation in Great Britain: Not for Long, but Here to Stay." Journal of the Royal Statistical Society Series A 163(2): $153-71$.

[23] Gautier, Pieter, Michael Svarer, and Coen Teulings. 2006. "Marriage and the City." Manuscript, Tinbergen Institute, Amsterdam.

[24] Giolito, Eugenio P. 2004. "A Search Model of Marriage with Differential Fecundity." IZA Discussion Paper No. 1082.

[25] Goldin, Claudia. 1991. "Marriage Bars: Discrimination against Married Women Workers from the 1920s to the 1950s." In Favorites of Fortune, edited by P. Higonnet, D.S. Landes, and H. Rosovsky. Cambridge, MA: Harvard University Press. 
[26] Goldin, Claudia. 2006. "The Quiet Revolution That Transformed Women's Employment, Education, and Family." American Economic Review Papers and Proceedings 96 (May): 1-21.

[27] Hajnal, J. 1965. "European Marriage Patterns in Perspective." In Population in History, edited by D.V. Glass and D.E.C. Eversley. London: Edward Arnold (Publishers).

[28] Hall, Robert E. 2005. "Employment Fluctuations with Equilibrium Wage Stickiness." American Economic Review 95 (March): 50-65.

[29] Lancaster, Tony. 1990. The Econometric Analysis of Transition Data. Cambridge: Cambridge University Press.

[30] Leech, Stewart. 2000. "With All My Worldly Goods I Thee Endow': The Status of Pre-nuptial Agreements in England and Wales." Family Law Quarterly 34 (Summer): 193-207.

[31] Lundberg, Shelly, and Robert A. Pollak. 1993. "Separate Spheres Bargaining and the Marriage Market." Journal of Political Economy 101 (December): 988-1010.

[32] Lundberg, Shelly, and Robert A. Pollak. 2003. "Efficiency in Marriage." Review of Economics of the Household 1 (September): 153-67.

[33] Masters, Adrian. 2006. "Marriage, Commitment and Divorce in a Matching Model with Differential Ageing." Manuscript, SUNY Albany.

[34] Mazzocco, Maurizio. 2006. "Household Intertemporal Behavior: A Collective Characterization and a Test of Commitment." Review of Economic Studies, forthcoming.

[35] Nasheri, Hedieh. 1998. "Prenuptial Agreements in the United States: A Need for Closer Control?" International Journal of Law, Policy and the Family 12 (December): $307-22$.

[36] Office for National Statistics. 2006. Marriage, Divorce and Adoption Statistics: Review of the Registrar General on Marriages and Divorces in 2003, and Adoptions in 2004, in England and Wales. Series FM2 No. 31. London: HMSO.

[37] Rose, S. O. 1992. Limited Livelihoods: Gender and Class in Nineteenth-Century England. London: Routledge. 
[38] Ruggles, S., et al. 2004. Integrated Public Use Microdata Series. Version 3.0. Minneapolis: Minnesota Population Center.

[39] Schoen, Robert, and Vladimir Canudas-Romo. 2005. "Timing Effects on First Marriage: Twentieth-Century Experience in England and Wales and the USA." Population Studies 59 (July): 135-46.

[40] Shimer, Robert, and Lones Smith. 2000. "Assortative Matching and Search." Econometrica 68 (March): 343-69.

[41] Siow, Aloysius. 1998 "Differential Fecundity, Markets, and Gender Roles." Journal of Political Economy 106 (April): 334-54.

[42] Smith, Lones. 2006. "The Marriage Model with Search Frictions." Journal of Political Economy 114 (December): 1124-44.

[43] Spuhler, J.N. 1972. "Behaviour and Mating Patterns in Human Populations." In The Structure of Human Population, edited by G.A. Harrison and A.J. Boyce. Oxford: Clarendon Press.

[44] Teulings, Coen N., Pieter A. Gautier. 2004. "The Right Man for the Job." Review of Economic Studies 71 (April): 553-80.

[45] United Nations. 1990. Patterns of First Marriage: Timing and Prevalence. New York: United Nations, Department of International Economic and Social Affairs.

[46] Weitzman, Lenore J. 1981. The Marriage Contract: Spouses, Lovers, and the Law. New York: Free Press.

[47] Wong, Linda Y. 2003. "Structural Estimation of Marriage Models", Journal of Labor Economics 21 (July): 699-727. 
Figure 1. Toyboys and toygirls in the US and the UK

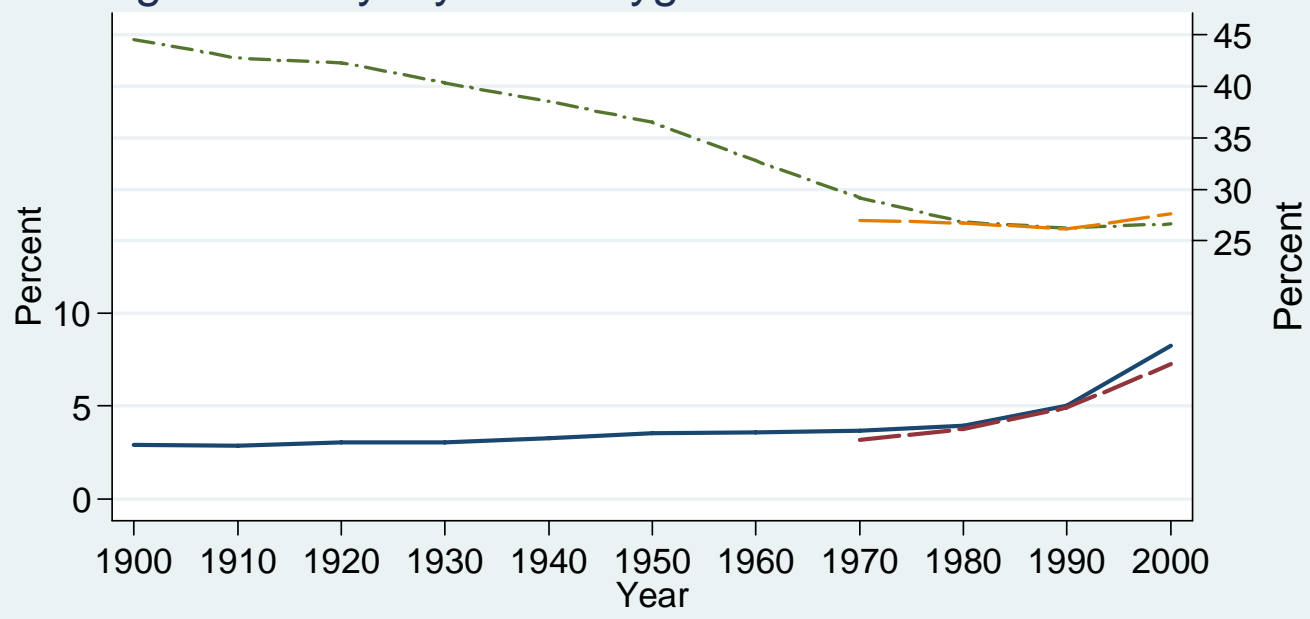

\begin{tabular}{|l}
\hline US, toyboy $\quad---$ UK, toyboy \\
$-\cdot-\cdot-\cdot$ US, toygirl $\quad---$ UK, toygirl
\end{tabular}

Note: Data for the United States are from the IPUMS 1900-2000. The data for the UK are from the ONS Londitudinal Study 1971-2001 (see text). Couples include both married

and cohabiting unions. Figures refer to couples in which the woman is aged less than 60 .

A woman is married to a toyboy if she is 5 or more years older. Toygirls are similarly defined.

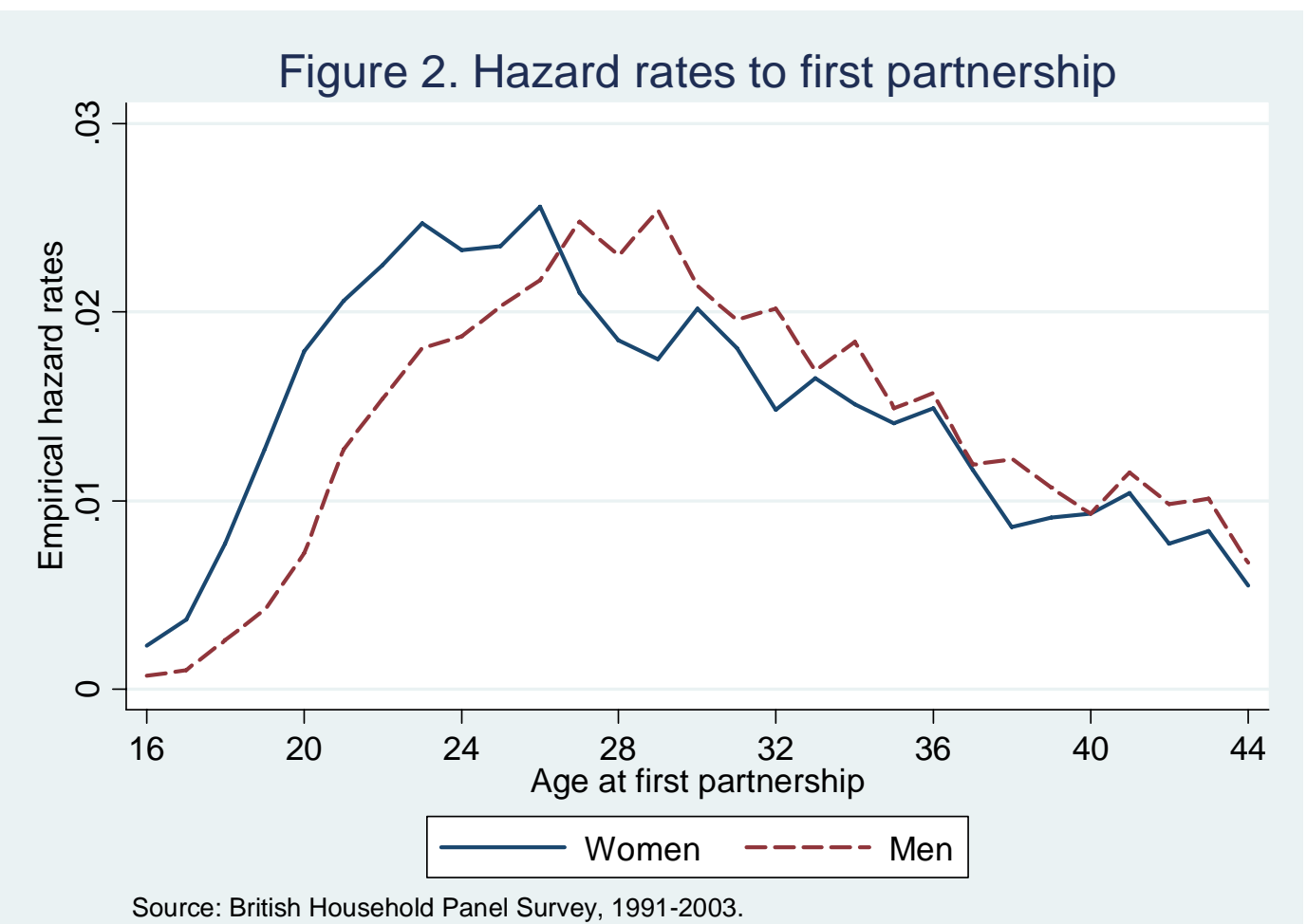


Figure 3. Matching Sets for the Case $\lambda=0$

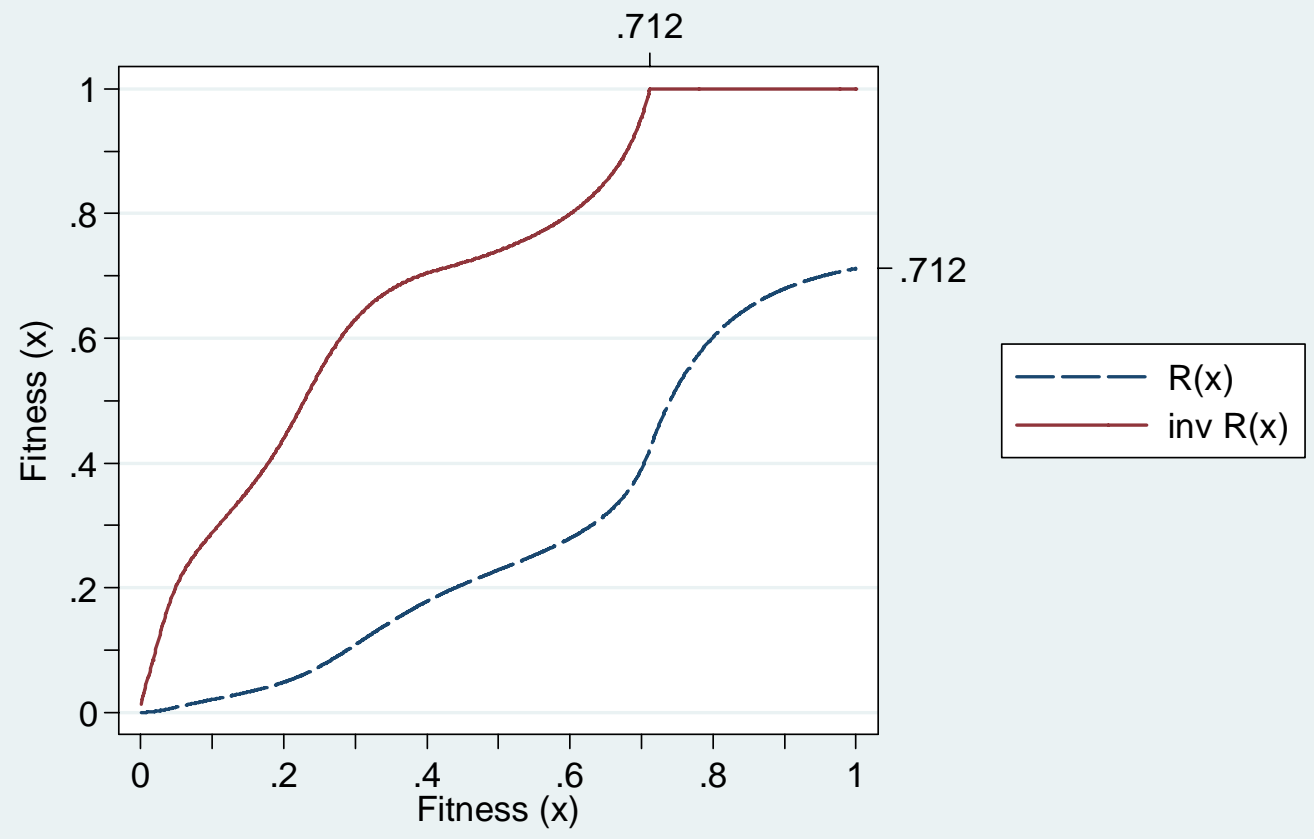

Note: " $\mathrm{R}(\mathrm{x})$ " denotes the reservation fitness, and the value 0.712 corresponds to $\overline{\mathrm{R}}$; " inv $\mathrm{R}(\mathrm{x})$ " is the inverse function of $\mathrm{R}(\mathrm{x})$.

Figure 4. Matching Sets LL (Toyboys)

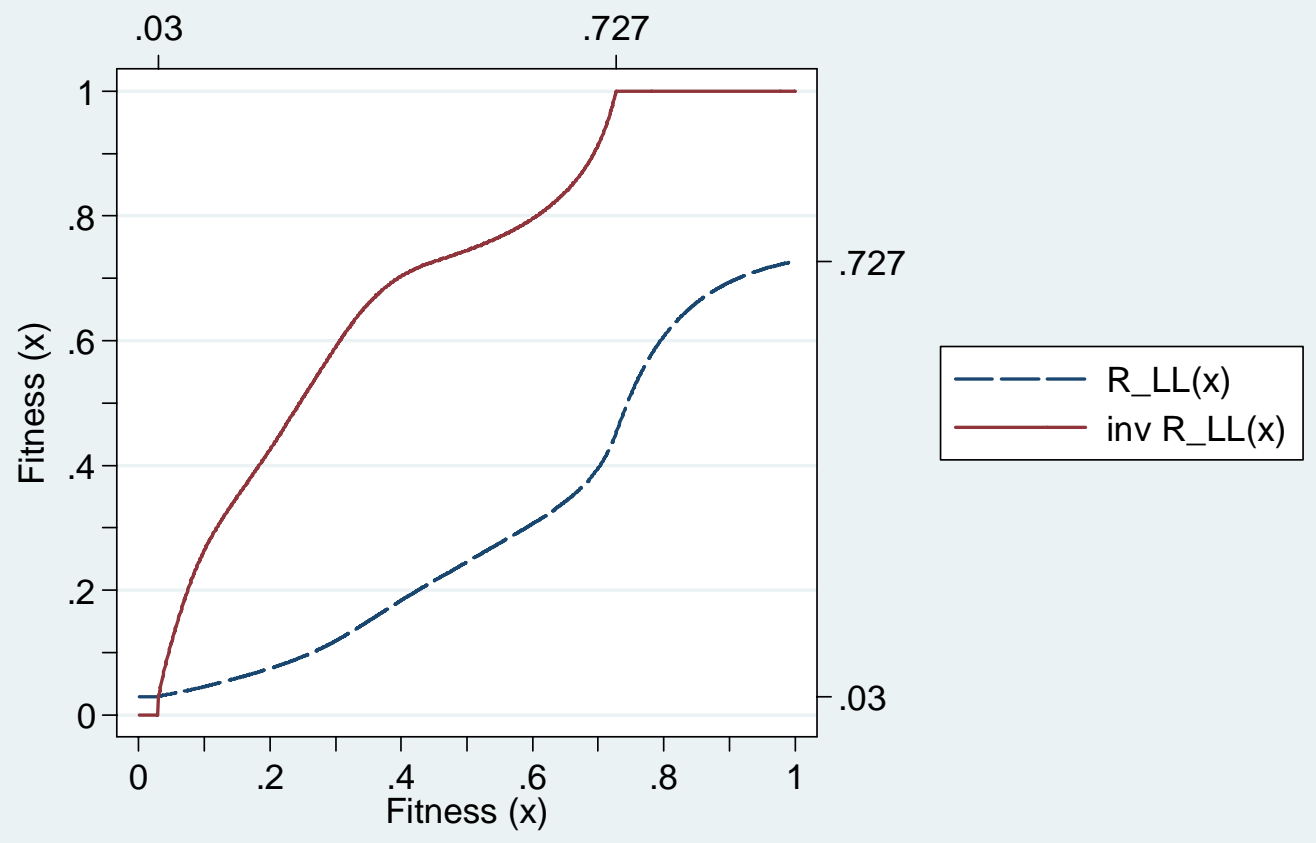

Note: "R_LL(x)" is the reservation match of a type "L" given contact with another type "L"; "inv R_LL(x)" is the acceptance set of a type " $\mathrm{L}$ " given contact with another type " $\mathrm{L}$ ". 
Figure 5. Matching Sets HL (Toyboys)

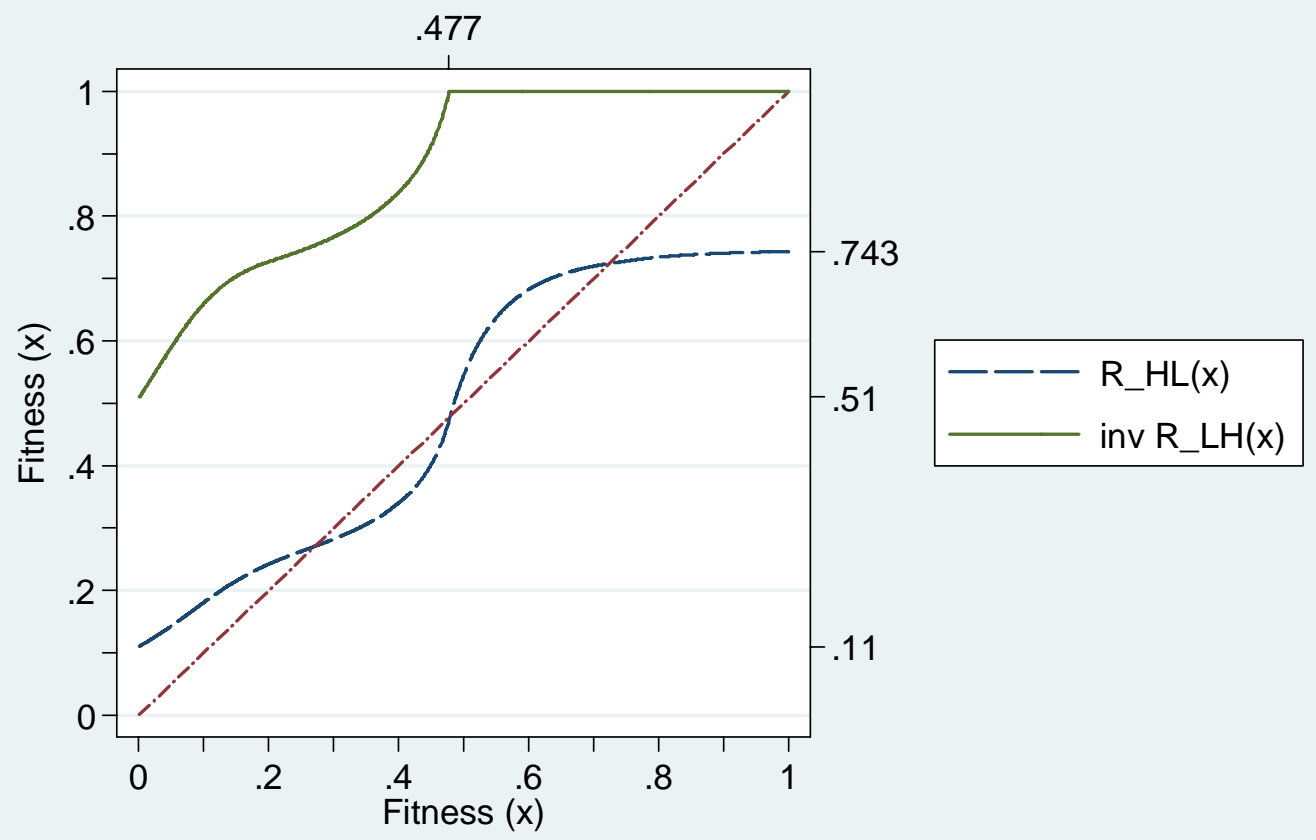

Note: "R_HL(x)" is the reservation match of a type "H" given contact with a type "L"; "inv R_LH(x)" is the acceptance set of a type "H" given contact with a type "L".

Figure 6. Reservation Fitness Rules (Glass Ceilings)

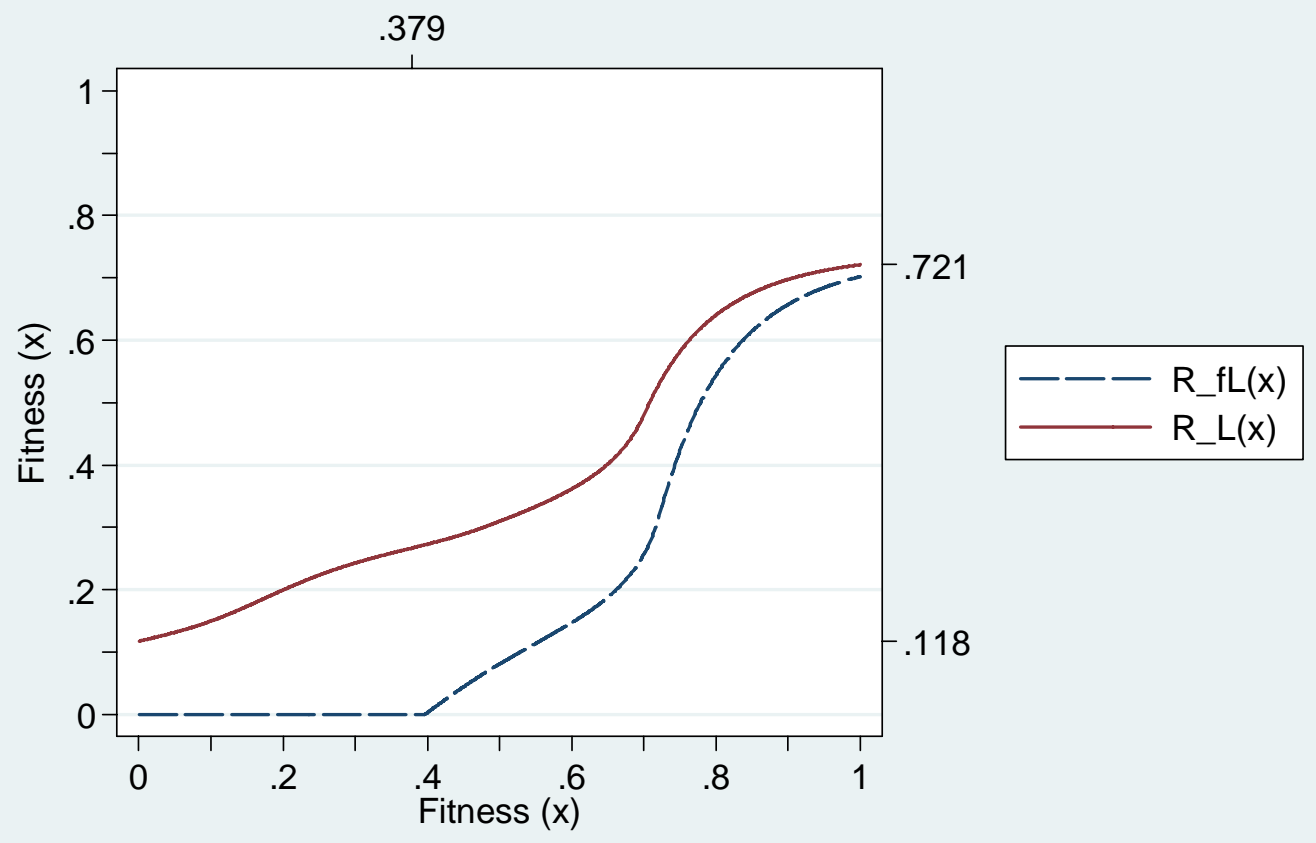

Note: " $\mathrm{R} \_\mathrm{fL}(\mathrm{x})$ " is the reservation fitness of a woman given contact with an unsuccessful man; " $\mathrm{R} \_\mathrm{L}(\mathrm{x})$ " is the reservation fitness of an unsuccessful man. 
Figure 7. Densities (Glass Ceilings)

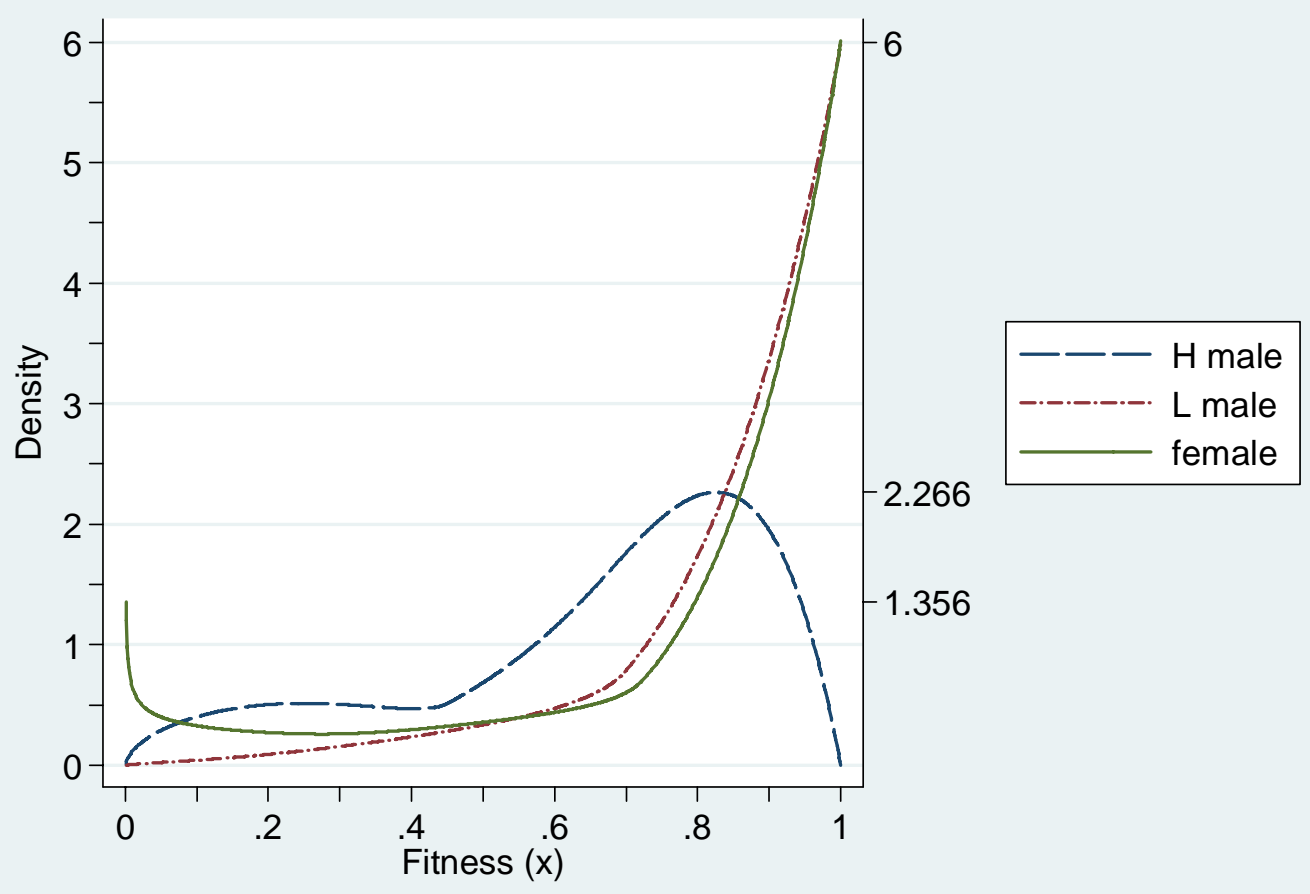

Note: "H male” denotes a successful male; "L male" denotes an unsuccessful male.

Figure 8. Marriage Hazard Rates (Glass Ceilings)

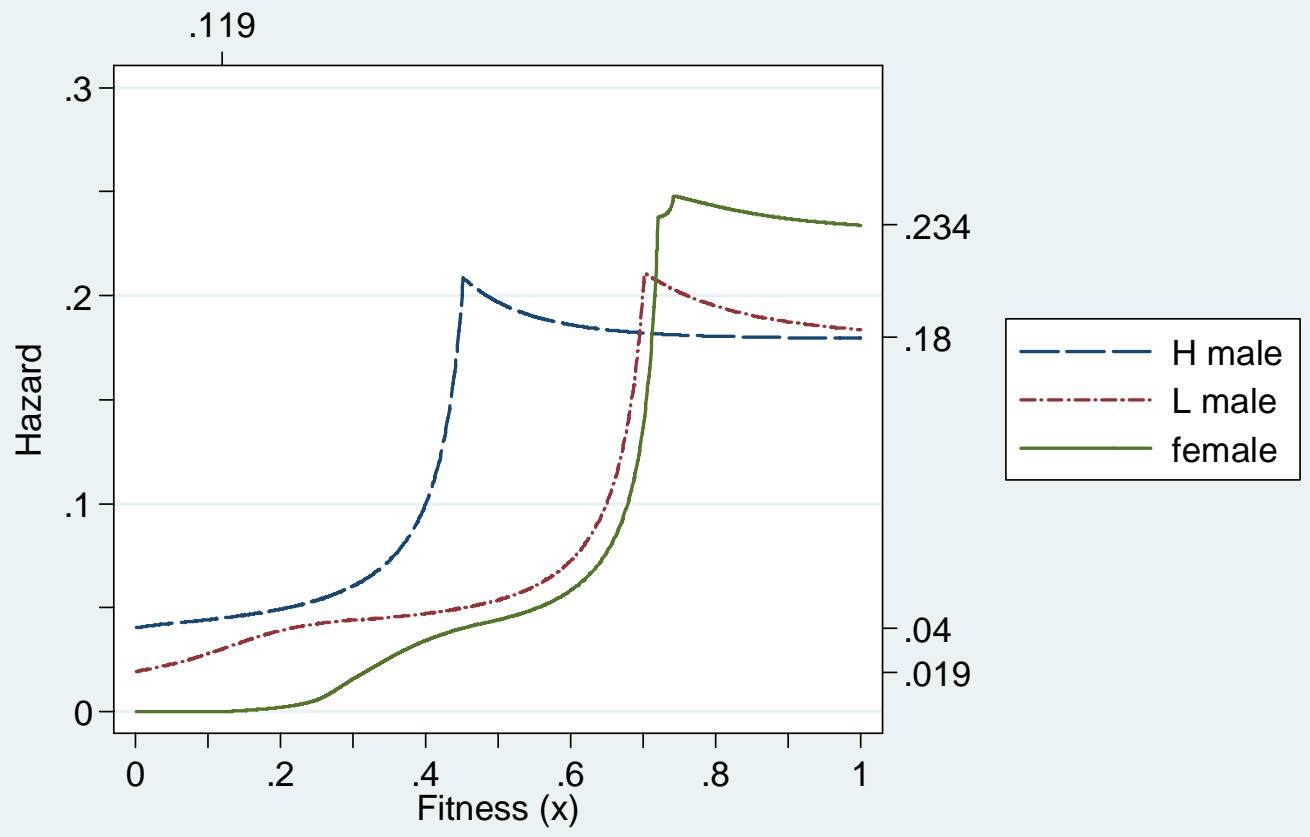

Note: "H male" denotes a successful male; "L male" denotes an unsuccessful male. 


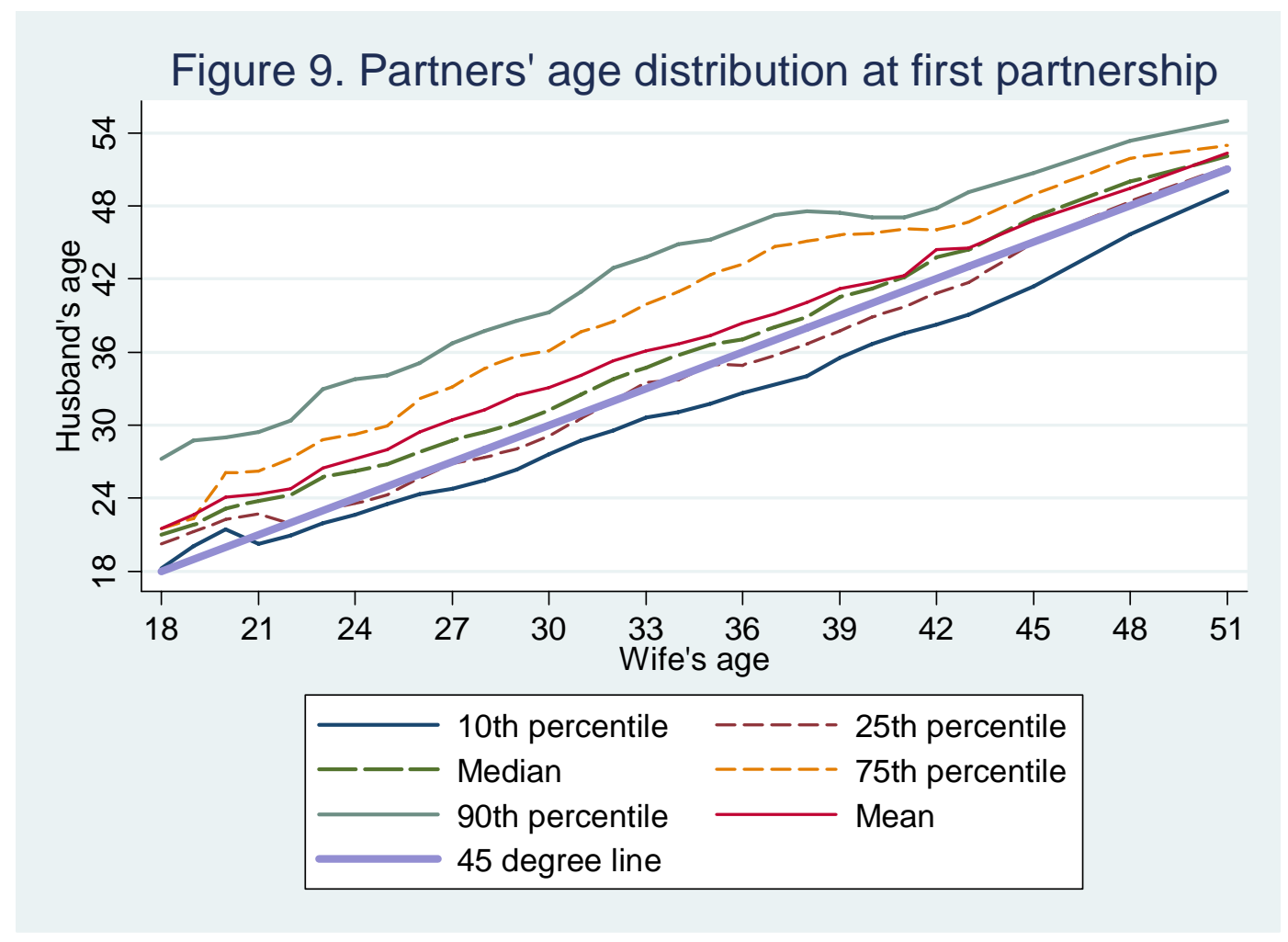

Source: British Household Panel Survey, 1991-2003.

Note: 'Husband' and 'wife' refer to all (married and cohabiting) partners. Means and percentiles are computed from the husband's distribution at any given age of the wife. 
Table 1

The Relationship between Fitness and Age Used in the Numerical Exercise

\begin{tabular}{lcccccccc}
\hline Age & 20 & 25 & 30 & 35 & 40 & 50 & 60 & 80 \\
Fitness $(x)$ & 1.00 & 0.84 & 0.70 & 0.59 & 0.50 & 0.35 & 0.25 & 0.12 \\
\hline
\end{tabular}

Table 2

Determinants of the Probability that the Woman is at Least 5 Years Older than Her Partner

Great Britain (Marginal Effects from Probit Estimates; N=781,780)

\begin{tabular}{|c|c|c|c|c|}
\hline Variable & 1971 & 1981 & 1991 & 2001 \\
\hline Baseline probability & 0.029 & 0.035 & 0.047 & 0.071 \\
\hline Woman has university degree or more & $\begin{array}{l}\mathbf{0 . 0 0 4} \\
(2.09)\end{array}$ & $\begin{array}{l}\mathbf{0 . 0 0 4} \\
(2.12)\end{array}$ & $\begin{array}{l}\mathbf{0 . 0 0 3} \\
(2.23)\end{array}$ & $\begin{array}{l}0.003 \\
(1.44)\end{array}$ \\
\hline Man has university degree or more & $\begin{array}{l}0.002 \\
(0.80)\end{array}$ & $\begin{array}{l}0.003 \\
(1.24)\end{array}$ & $\begin{array}{l}0.001 \\
(1.07)\end{array}$ & $\begin{array}{l}0.002 \\
(0.56)\end{array}$ \\
\hline Woman is more educated than her partner & $\begin{array}{l}\mathbf{0 . 0 0 9} \\
(3.15)\end{array}$ & $\begin{array}{l}\mathbf{0 . 0 0 9} \\
(3.77)\end{array}$ & $\begin{array}{l}\mathbf{0 . 0 1 1} \\
(5.06)\end{array}$ & $\begin{array}{l}\mathbf{0 . 0 1 3} \\
(7.94)\end{array}$ \\
\hline $\begin{array}{l}\text { Woman and her partner have same } \\
\text { education level }\end{array}$ & $\begin{array}{l}0.002 \\
(1.41)\end{array}$ & $\begin{array}{l}0.002 \\
(1.15)\end{array}$ & $\begin{array}{l}0.001 \\
(1.28)\end{array}$ & $\begin{array}{l}0.001 \\
(0.85)\end{array}$ \\
\hline Woman’s occupation: & & & & \\
\hline Professional & $\begin{array}{l}\mathbf{0 . 0 0 4} \\
(2.84)\end{array}$ & $\begin{array}{l}\mathbf{0 . 0 0 4} \\
(2.58)\end{array}$ & $\begin{array}{l}\mathbf{0 . 0 0 5} \\
(3.32)\end{array}$ & $\begin{array}{l}\mathbf{0 . 0 0 6} \\
(4.34)\end{array}$ \\
\hline Managerial & $\begin{array}{l}\mathbf{0 . 0 0 3} \\
(3.11)\end{array}$ & $\begin{array}{l}\mathbf{0 . 0 0 4} \\
(3.58)\end{array}$ & $\begin{array}{l}\mathbf{0 . 0 0 4} \\
(3.70)\end{array}$ & $\begin{array}{l}\mathbf{0 . 0 0 8} \\
(3.57)\end{array}$ \\
\hline Skilled non-manual & $\begin{array}{l}-\mathbf{0 . 0 0 6} \\
(3.18)\end{array}$ & $\begin{array}{l}-\mathbf{- 0 . 0 0 4} \\
(2.74)\end{array}$ & $\begin{array}{l}-\mathbf{- 0 . 0 0 5} \\
(2.47)\end{array}$ & $\begin{array}{l}-0.005 \\
(2.88)\end{array}$ \\
\hline Skilled manual & $\begin{array}{l}-\mathbf{0 . 0 0 4} \\
(2.17)\end{array}$ & $\begin{array}{l}\mathbf{- 0 . 0 0 4} \\
(2.74)\end{array}$ & $\begin{array}{r}\mathbf{- 0 . 0 0 3} \\
(2.41)\end{array}$ & $\begin{array}{l}\mathbf{- 0 . 0 0 4} \\
(2.36)\end{array}$ \\
\hline Man’s occupation: & & & & \\
\hline Professional & $\begin{array}{r}\mathbf{- 0 . 0 1 0} \\
(3.10)\end{array}$ & $\begin{array}{l}\mathbf{- 0 . 0 0 4} \\
(2.39)\end{array}$ & $\begin{array}{r}\mathbf{- 0 . 0 0 7} \\
(2.89)\end{array}$ & $\begin{array}{l}\mathbf{- 0 . 0 0 8} \\
(2.67)\end{array}$ \\
\hline Managerial & $\begin{array}{l}\mathbf{- 0 . 0 1 3} \\
(2.84)\end{array}$ & $\begin{array}{r}-\mathbf{0 . 0 0 9} \\
(3.11)\end{array}$ & $\begin{array}{r}\mathbf{- 0 . 0 1 0} \\
(3.22)\end{array}$ & $\begin{array}{l}-\mathbf{0 . 0 1 1} \\
(3.06)\end{array}$ \\
\hline Skilled non-manual & $\begin{array}{l}-0.002 \\
(0.54)\end{array}$ & $\begin{array}{l}-0.002 \\
(0.73)\end{array}$ & $\begin{array}{l}-0.002 \\
(0.48)\end{array}$ & $\begin{array}{l}-0.002 \\
(0.74)\end{array}$ \\
\hline Skilled manual & $\begin{array}{l}-0.002 \\
(1.04)\end{array}$ & $\begin{array}{l}-0.001 \\
(1.16)\end{array}$ & $\begin{array}{l}-0.003 \\
(1.52)\end{array}$ & $\begin{array}{l}-0.005 \\
(1.13)\end{array}$ \\
\hline $\begin{array}{l}\text { Woman has better occupation than her } \\
\text { partner }\end{array}$ & $\begin{array}{l}\mathbf{0 . 0 0 6} \\
(2.67)\end{array}$ & $\begin{array}{l}\mathbf{0 . 0 0 8} \\
(2.51)\end{array}$ & $\begin{array}{l}\mathbf{0 . 0 1 2} \\
(5.20)\end{array}$ & $\begin{array}{l}\mathbf{0 . 0 1 9} \\
(9.59)\end{array}$ \\
\hline $\begin{array}{l}\text { Woman and her partner have same } \\
\text { occupational level }\end{array}$ & $\begin{array}{l}0.004 \\
(1.38)\end{array}$ & $\begin{array}{l}0.008 \\
(1.70)\end{array}$ & $\begin{array}{l}\mathbf{0 . 0 0 7} \\
(2.89)\end{array}$ & $\begin{array}{r}\mathbf{0 . 0 1 0} \\
(4.71)\end{array}$ \\
\hline Number of couples & 200,794 & 199,266 & 183,048 & 198,672 \\
\hline
\end{tabular}

Source: ONS Longitudinal Survey.

Note: Robust $t$ statistics are in parentheses. Estimates in bold are significant at the 5 percent level. The figures are estimates of the interactions of each listed variable and year. The other variables included in estimation (which have not been interacted with year) are a quartic polynomial in age (of the woman), and indicators for nonwhite ethnic origin of the woman, number of children, region of residence, non-working status of the woman, and year. 
Table 3

The Effects of Relative Education and Relative Income on the Probability that the Woman is at Least 5 Years Older than Her Partner United States (Marginal Effects from Probit Estimates; N=2,781,081)

\begin{tabular}{|c|c|c|c|c|c|}
\hline Selected variables & 1960 & 1970 & 1980 & 1990 & 2000 \\
\hline Baseline probability & 0.037 & 0.036 & 0.039 & 0.049 & 0.088 \\
\hline $\begin{array}{l}\text { Woman is more educated than her } \\
\text { partner }\end{array}$ & $\begin{array}{r}\mathbf{0 . 0 0 4} \\
(4.13)\end{array}$ & $\begin{array}{r}\mathbf{0 . 0 0 5} \\
(7.12)\end{array}$ & $\begin{array}{r}\mathbf{0 . 0 0 5} \\
(7.88)\end{array}$ & $\begin{array}{r}\mathbf{0 . 0 0 7} \\
(9.71)\end{array}$ & $\begin{array}{r}\mathbf{0 . 0 1 2} \\
(16.79)\end{array}$ \\
\hline $\begin{array}{l}\text { Woman has higher income than her } \\
\text { partner }\end{array}$ & $\begin{array}{r}0.001 \\
(1.37)\end{array}$ & $\begin{array}{r}\mathbf{0 . 0 0 7} \\
(7.00)\end{array}$ & $\begin{array}{r}\mathbf{0 . 0 0 7} \\
(8.90)\end{array}$ & $\begin{array}{r}\mathbf{0 . 0 1 5} \\
(18.06)\end{array}$ & $\begin{array}{r}\mathbf{0 . 0 1 2} \\
(13.19)\end{array}$ \\
\hline Number of couples & 393,697 & 436,334 & 490,177 & 532,744 & 564,474 \\
\hline
\end{tabular}

Source: IPUMS 1 percent samples.

Note: Robust $t$ statistics are in parentheses. Estimates in bold are significant at the 5 percent level. The figures are estimates of the interactions of each listed variable and year. The other variables included in estimation (which have not been interacted with year) are a quartic polynomial in age (of the woman), and indicators for nonwhite ethnic origin of the woman, her education (three dummy variables), her total personal income, her partner's education (three dummy variables), region of residence, and Census year. All income figures are deflated by the CPI All Urban Consumers series CUUR0000SA0. 'Income' refers to total personal income (IPUMS variable is INCTOT) for all census years. 